\title{
Improving the Ghanaian Safe Motherhood Programme
}

Ivy Osei

Bertha Garshong

Gertrude Banahene

John Gyapong

Placide Tapsoba

Population Council

See next page for additional authors

Follow this and additional works at: https://knowledgecommons.popcouncil.org/departments_sbsr-rh

Part of the Demography, Population, and Ecology Commons, International Public Health Commons, Maternal and Child Health Commons, and the Women's Health Commons How does access to this work benefit you? Let us know!

\section{Recommended Citation}

Osei, Ivy, Bertha Garshong, Gertrude Banahene, John Gyapong, Placide Tapsoba, lan Askew, Clement Ahiadeke, Richard Killian, Edward Bonku, Perle Combary, and William Sampson. 2005. "Improving the Ghanaian Safe Motherhood Programme," FRONTIERS Final Report. Washington, DC: Population Council. 


\section{Authors}

Ivy Osei, Bertha Garshong, Gertrude Banahene, John Gyapong, Placide Tapsoba, lan Askew, Clement Ahiadeke, Richard Killian, Edward Bonku, Perle Combary, and William Sampson 


\title{
IMPROVING THE GHANAIAN SAFE MotherhoOd Programme
}

\author{
Evaluating the effectiveness of alternative training \\ models and other performance improvement factors on the \\ quality of maternal care and client outcomes
}

Health Research Unit, Ghana Health Services

Ivy Osei, Bertha Garshong, Gertrude Owusu Banahene, John Gyapong

Frontiers Program / Population Council

Placide Tapsoba, Ian Askew, Clement Ahiadeke

PRIME II / IntraHealth International

Richard Killian, Edward Bonku, Perle Combary, William Sampson

\section{March 2005}

This study was funded by the UNITED STATES AGENCY FOR INTERNATIONAL DEVELOPMENT (USAID) under the terms of the Cooperative Agreement Number HRN-A00-98-00012-00 and Population Council. The opinions expressed herein are those of the authors and do not necessarily reflect the views of USAID. 


\section{Table of Contents}

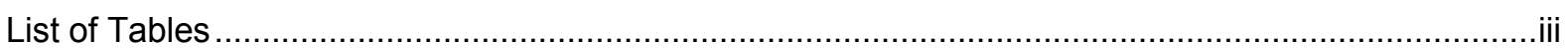

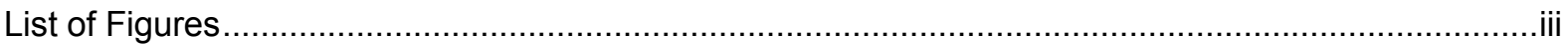

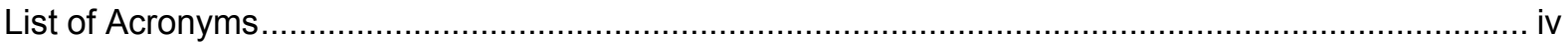

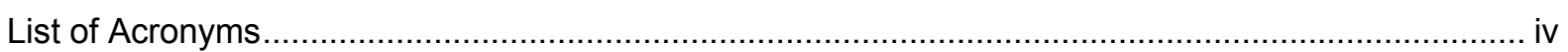

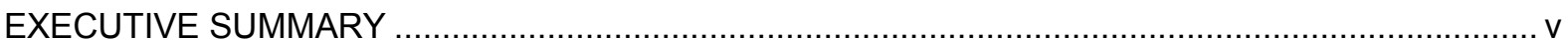

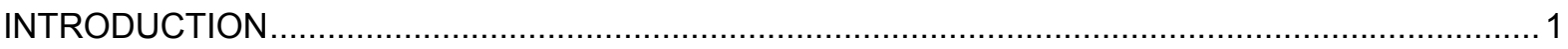

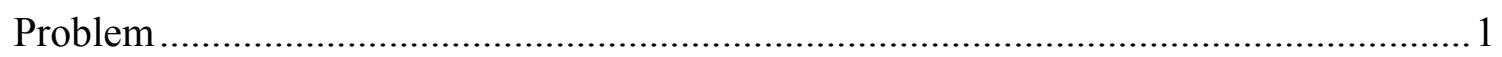

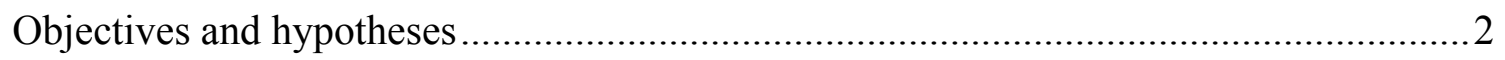

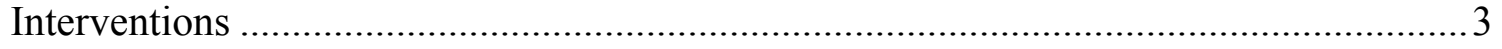

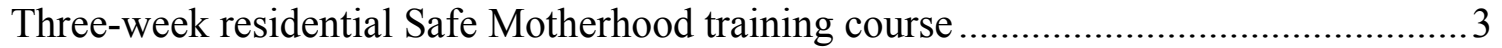

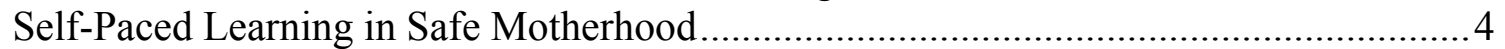

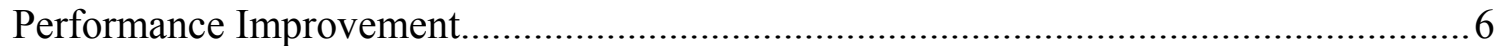

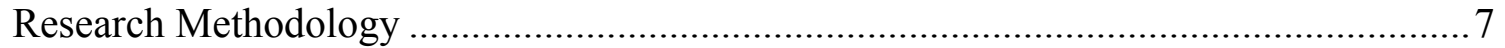

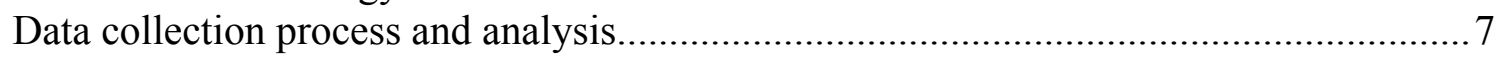

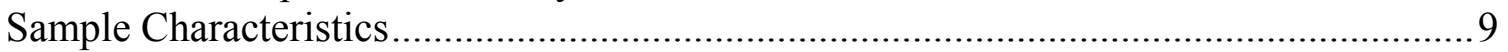

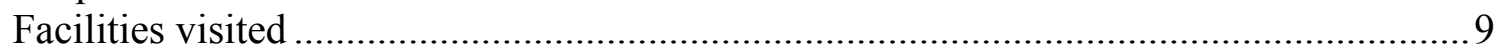

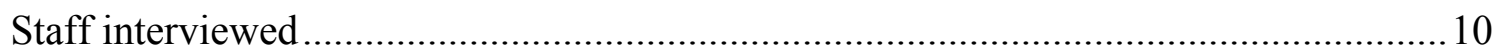

Clients observed

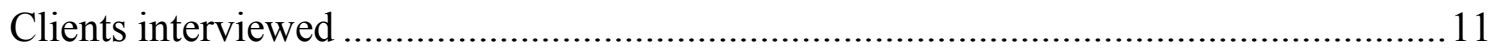

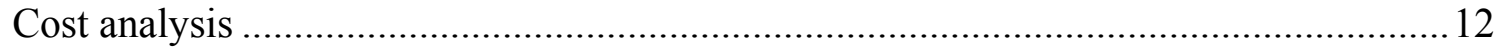

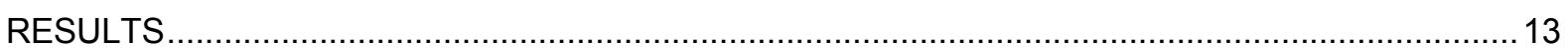

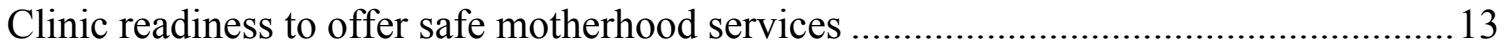

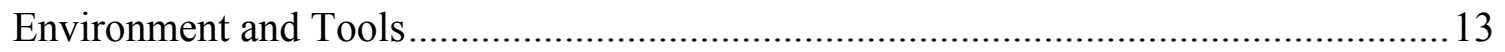

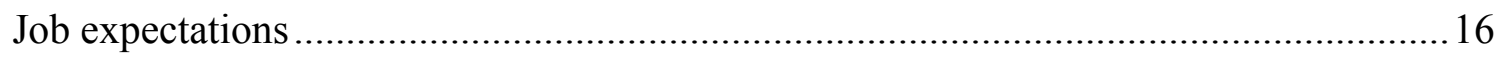

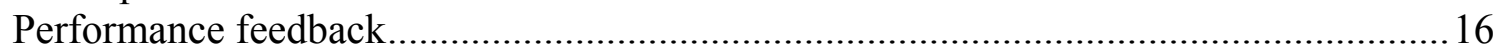

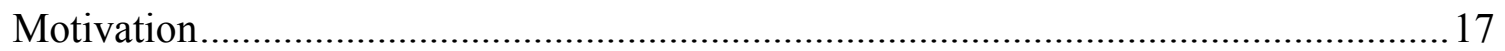

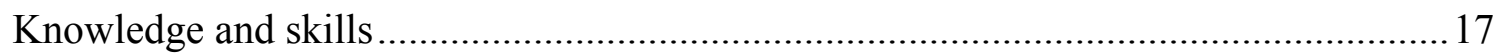

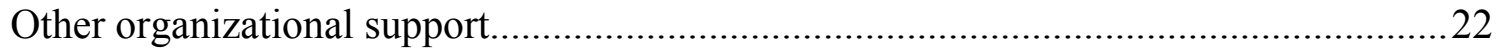

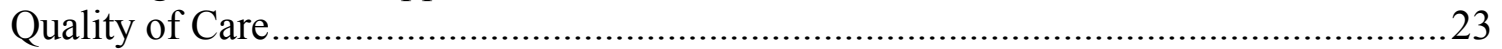

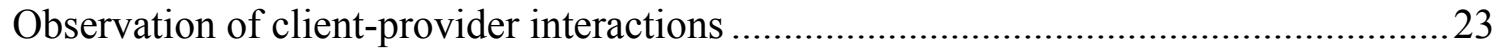

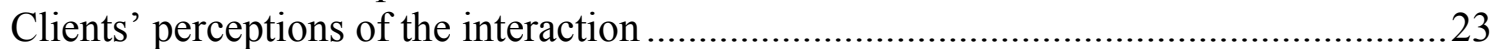

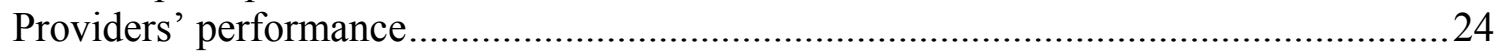

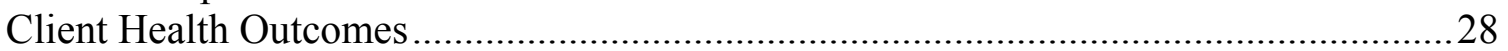

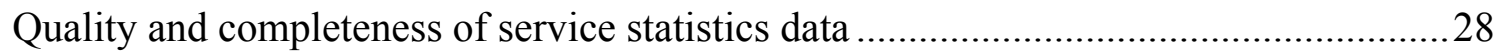

Volume of services recorded during the last calendar year .........................................28

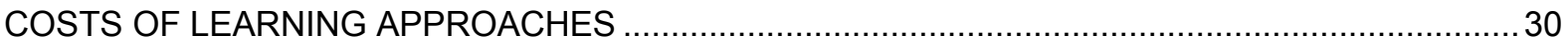

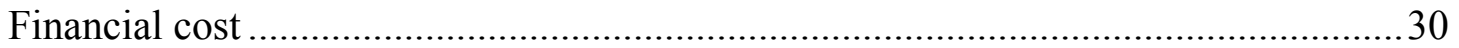

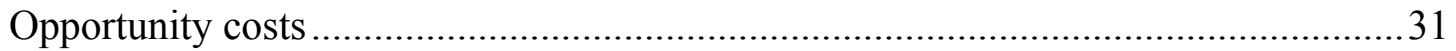

Cost-effectiveness of the SPL and Traditional approaches .........................................34

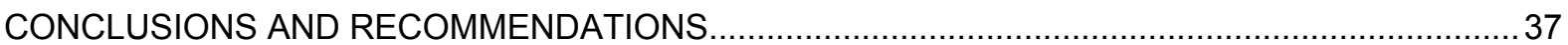




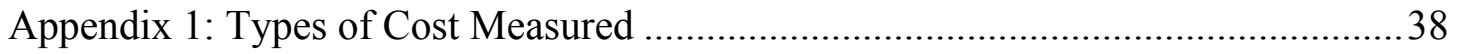

Appendix 2: Volume of services provided during January 1-December 31 2001, by

type of facility 


\section{List of Tables}

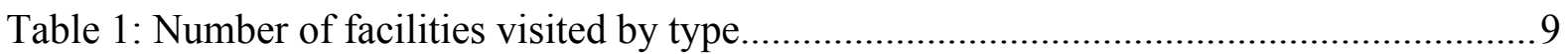

Table 2: Characteristics of staff interviewed by type of training intervention ........................ 10

Table 3: Number of cases observed (baseline) or simulated (endline) .................................. 11

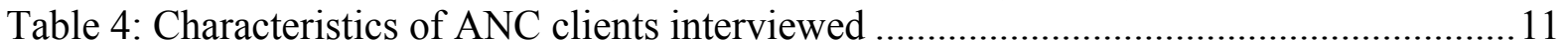

Table 5: Category of personnel interviewed for the cost analysis at endline ......................... 12

Table 6: Number of health centres lacking selected equipment and supplies ........................ 14

Table 7: Availability of IEC material in the facilities (Hospitals and Health Centres) ........... 15

Table 8: Group mean score for providers' knowledge of ANC indicators .............................. 18

Table 9: Group mean score for provider knowledge on labour and delivery ..........................20

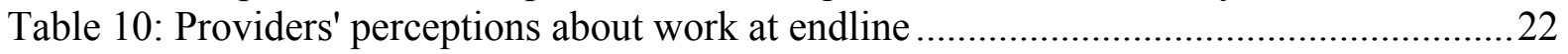

Table 11: Provider performance in Routine ANC ................................................................23

Table 12: Group mean score of provider performance in Emergency Obstetric Care and

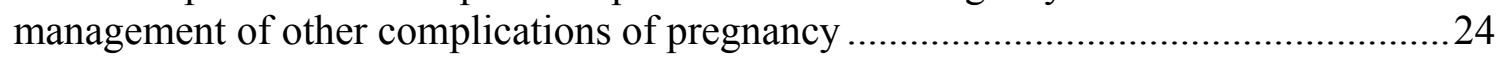

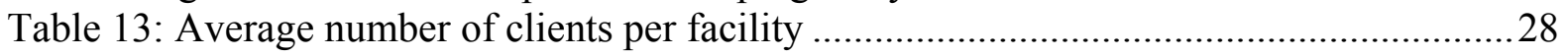

Table 14: Financial cost of SPL and Traditional training approaches.................................29

Table 15: Average hours and value of time per personnel category by approach................... 31

Table 16: Cost-effectiveness analysis of the SPL and Traditional Residential learning approaches.

\section{List of Figures}

Figure 1: Indicators of provider knowledge in ANC by study group ................................... 18

Figure 2: Providers scoring 70\% and above in ANC knowledge assessment at endline........ 19

Figure 3: Comparison of group score of provider knowledge of labour and delivery ............21

Figure 4: Providers scoring $70 \%$ and above in labour and delivery knowledge at endline.....22

Figure 5: Providers' performance and skills in emergency obstetric care ..............................25

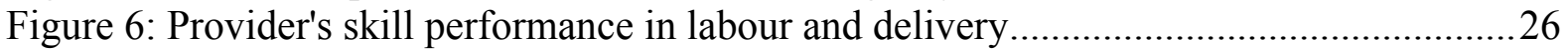

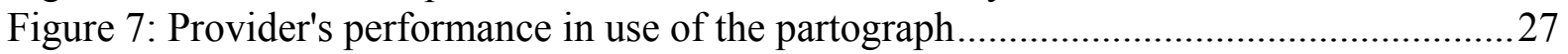

Figure 8: Group comparison of provider performance in Partograph analysis .....................27

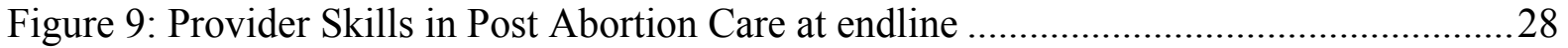

Figure 10: Financial cost of SPL approach.......................................... 30

Figure 11: Financial cost of Traditional approach....................................... 31

Figure 12: Percentage of learner time by category of activities (SPL) .................................. 33

Figure 13: Combined Financial and Opportunity costs per learner....................................... 34 


\section{List of Acronyms}

\begin{tabular}{|c|c|}
\hline ANC & Antenatal Care \\
\hline DHA & District Health Administration \\
\hline DL & Distance Learning \\
\hline FP & Family Planning \\
\hline GHS & Ghana Health Services \\
\hline HRU & Health Research Unit \\
\hline IEC & Information, Education and Communication \\
\hline IUD & Intrauterine Contraceptive Device \\
\hline IV & Intravenous \\
\hline LSS & Life-Saving Skills \\
\hline MVA & Manual Vacuum Aspiration \\
\hline $\mathrm{OB} / \mathrm{GYN}$ & Obstetric and Gynaecology \\
\hline OJT & On-the-Job Training \\
\hline PAC & Post-Abortion Care \\
\hline PI & Performance Improvement \\
\hline PNA & Performance Needs Assessment \\
\hline PNC & Postnatal Care \\
\hline $\mathrm{RCH}$ & Reproductive and Child Health \\
\hline RHA & Regional Health Administration \\
\hline RRT & Regional Resource Team \\
\hline SPL & Self-Paced Learning \\
\hline SDP & Service Delivery Point \\
\hline SM & Safe Motherhood \\
\hline
\end{tabular}




\section{Executive Summary}

In 1995, the Ghana Health Services (GHS) of the Ministry of Health (MOH) launched the National Safe Motherhood (SM) Programme, the focus of which is to reduce the high levels of maternal mortality and morbidity through improving the quality and coverage of maternal health services, and to increase awareness about maternal health issues in communities. Since 1998, PRIME II, a global project funded by USAID and managed by IntraHealth International for the training and support of primary reproductive health providers, has provided assistance to strengthen the training, supervision and referral capacity of the MOH's Regional Resource Teams (RRT). Training in safe motherhood knowledge and skills was initially provided through a combination of theoretical and practical work during a 3-week residential course. An assessment of this training approach raised several concerns, notably, that trainees were away from their facilities for a substantial amount of time, thus restricting access to services, and that many trainees were not able to complete their practical training due to low client caseloads and the high number of trainees at the training sites at one time.

Scaling up of the SM programme to the three northern regions began in 2000 with a Performance Needs Assessment (PNA), which measured the current performance levels of the RRTs against a desired status determined by national standards, identified causes of the gaps found, and proposed interventions for eliminating or reducing these gaps. Consequently, the GHS and PRIME II reviewed and revised the existing interventions to include a competency-based Life Saving Skills (LSS) training to minimize existing implementation gaps and to increase the impact of such interventions on provider and clinic performance. In addition, PRIME II had successfully tested an innovative approach to in-service training, a modular Self-Paced Learning (SPL) approach, combined with an extensive learner support system, for trainee-midwives of the private sector Ghana Registered Midwives Association (GRMA), and this experience suggested that this SPL approach may be relevant when scaling up the SM programme.

With the level of investment needed for expanding the SM programme, it was felt important to assess whether the SPL training approach would be at least or more cost-effective than the existing 3-week residential approach. Support was requested from the Population Council's USAID-funded Frontiers in Reproductive Health programme to assist PRIME II and the GHS to undertake an operations research study to prospectively evaluate and compare the costeffectiveness of these two training approaches and other performance improvement interventions.

The study measured and compared changes in provider knowledge and skills and the costs of implementing the three-week residential and the SPL approaches using a non-randomised pre-intervention post-intervention comparison group design. Data were collected through: inventories of equipment and supplies at each service delivery site; compilation of service statistics for the previous 12 months; interviews and practical assessments of all trained service providers to gauge their knowledge of safe motherhood services and procedures; observations of client-provider interactions during antenatal visits and exit interviews with the clients; and compilation of financial expenditures for all activities during implementation of each approach and estimation of the opportunity costs for staff time.

After the training, only providers in the SPL group exhibited improvements in their group mean summary scores for indicators of knowledge, with statistically significant improvements of 24 and 46 percent. In relation to indicators of provider performance, both 
approaches registered improvements across all three areas evaluated (i.e., routine ANC, managing obstetric and other complications, and PAC), but the only increase that was statistically significant was for skills in managing obstetric and other complications among the SPL group. Both groups performed well in labour and delivery skills; however, there was a statistically significant difference in the average score across the four skills of 70 percent in the intervention group compared to 74 percent in the comparison group.

The SPL approach costs more per trainer than the traditional residential approach, both in financial costs alone and when opportunity costs are added. A cost-effectiveness analysis showed that for improving provider knowledge, the SPL approach was clearly more costeffective because the traditional residential approach was not effective. When financial costs only were considered, there was no difference between the two approaches for improving routine ANC or PAC performance, but for EOC performance the SPL approach was more cost-effective. When opportunity costs were included, however, the residential approach was more cost-effective than the SPL approach across all three performance indicators.

A dissemination meeting held with stakeholders agreed that the SPL and residential approaches are not mutually exclusive - both approaches have their strengths and weaknesses. Training for safe motherhood should be developed based on the strengths of the two approaches. 


\section{Introduction}

In 1995 the Ghana Health Service (GHS) launched the National Safe Motherhood (SM) Programme to reduce maternal mortality and morbidity through improving the quality and coverage of maternal health services, and to increase awareness about maternal health issues in communities. Some of the services offered at health facilities that are being improved through the SM programme include the management of both routine and risk conditions in antenatal care, labour and delivery, and postnatal care. Since 1998, PRIME II, a USAIDfunded global project managed by IntraHealth International for the training and support of primary level reproductive health service providers, has provided assistance to strengthen the training, supervision and referral capacity of Regional Resource Teams (RRT), which in turn train and supervise primary providers.

Training for the SM programme was initially done using a combination of theoretical and practical work through a 3-week intensive residential course. In 1999-2000, PRIME II tested an innovative approach to in-service training among a number of private sector providers of the Ghana Registered Midwives Association (GRMA) in the Eastern, Brong Ahafo and Ashanti regions. The initiative involved a modular Self-Paced Learning (SPL) approach combined with an extensive learner support system designed for mature midwives who had been out of school for several years and for whom off-site training would be disruptive for the smooth operation of their clinics. For these private sector providers, time spent in off-site training also means a loss of income and reduced access to services for their clients. The conclusions of an assessment report found the initiative not only feasible and comprehensible, but also effective in increasing knowledge and skills of these providers. In addition, there was clear evidence of improved quality of care and client satisfaction with services provided by the midwives who had been trained using the SPL approach.

In 2000, the $\mathrm{MOH} / \mathrm{GHS}$ decided to expand the SM programme to three regions (Northern, Upper West and Upper East), with financial and technical assistance from PRIME II. The scale up began with PRIME II supporting the $\mathrm{MOH}$ to conduct a Performance Needs Assessment (PNA) in the three regions to measure the existing performance levels of the RRTs against the national standards, to identify causes of performance gaps, and to propose interventions for eliminating or reducing the gaps. This process, which is referred to as the Performance Improvement Approach (PIA), is a core competency of PRIME II and it has been applied in a number of other countries.

Several key lessons had been learned about training providers through the residential approach. Notably, trainees were away from their facilities for a substantial amount of time, and many trainees were not able to complete their practical training due to low client caseloads at the training sites and the presence of at least eight trainees at the training sites. The SPL approach had been designed to address these issues, as well as the challenge of sustainability, that is, establishing an effective approach to preparing providers to offer post abortion care/life saving skills/family planning (PAC/LSS/FP) services consistent with SM performance expectations and service standards.

\section{Problem}

With the information presented above, and the advent of scaling-up activities in the three regions of northern Ghana, it became imperative for the GHS and PRIME II to review and 
revise the existing approach so as to include a competency-based LSS for strengthening the performance of the SM programme, both to minimize existing implementation gaps and to increase the impact of such interventions on provider and clinic performance. As this marked the beginning of a nationwide scaling-up of the SM programme and involved substantial investment by the GHS and its development partners (e.g. USAID, UNFPA, UNICEF) over a long period of time, it was essential that the process be well monitored and adequately documented.

With this level of investment, it was important to confirm early on in the process that adapting the SPL training approach would be equally or more cost-effective than the existing 3-week residential approach. Moreover, given that there was widespread interest, both in Ghana and worldwide, in the feasibility and effectiveness of alternative in-service training approaches such as this, support and assistance was sought from the Population Council's FRONTIERS programme and the Health Research Unit (HRU) of the GHS to undertake an operations research project to document the implementation and evaluate and compare the cost-effectiveness of these two training approaches and other performance improvement interventions to address the following questions:

- Is the SPL approach a cost-effective way of in-service training in safe motherhood skills for public-sector primary providers?

- Does the SPL training approach contribute to the improvement of provider performance to the desired level?

- Do the training and other PI interventions result in improved clinic performance?

- What impact does a performance improvement program, with a strong emphasis on training and supervision, have on client health outcomes?

\section{Objectives and hypotheses}

This report describes a project that compared the cost-effectiveness of the two learning approaches. It specifically:

- Describes the quality and applicability of the Self-Paced Learning Approach (SPL)

- Measures and compares changes in provider knowledge and skills produced by the threeweek residential and SPL Safe Motherhood courses

- Evaluates and compares the effects of the three-week residential training with the SPL Safe Motherhood training and other Performance Improvement factors on the quality of services

- Measures and compares the cost of implementing the three-week residential and SPL Safe Motherhood courses.

The study tested the following hypotheses:

1. The knowledge and skills of those trained through the SPL approach to learning safe motherhood skills will be the same as or higher than those learning safe motherhood skills through the three-week residential safe motherhood training course.

2. The quality of safe motherhood services at clinics where at least one provider has received the SPL approach to training in safe motherhood skills and where other performance improvement factors have been implemented will be higher than clinics 
where at least one provider has attended the three-week safe motherhood residential training and there have been performance improvement activities.

3. Selected health outcomes of antenatal and delivery clients attending clinics where at least one provider has received the SPL approach to training in safe motherhood skills and where other performance improvement factors have been implemented will be higher than those attending clinics where at least one provider has attended the threeweek safe motherhood training and there have been performance improvement activities.

\section{Interventions}

The study assessed two training interventions: one intervention that trained primary providers in safe motherhood skills through a SPL approach, and the other that trained providers through the existing three-week residential approach. Other efforts, aimed at enhancing the environment in which supervisors and providers work to improve their performance, were implemented constantly in both groups of study sites.

\section{Three-week residential Safe Motherhood training course}

This is a three-week integrated SM clinical skill update programme, which focuses on integrated LSS and PAC training of midwives and back/up referral physicians. The content of the SM clinical skills update program includes:

- Infection prevention practices

- Antenatal risk assessment and management of pregnancy induced hypertension $(\mathrm{PIH})$, anaemia and acute postpartum haemorrhage

- Use of the partograph

- Infant resuscitation

- Postabortion care

- Postpartum and post abortion family planning counselling

- FP counselling and methods.

The RRTs were reconstituted, trained and equipped to perform their functions in training and supervision of service providers in the delivery of safe motherhood services. RRTs obtained competence after training by master trainers in applying the traditional approach, which basically involves organizing group or classroom-based training workshops for providers. Training time was devoted to teaching clinical skills and using, among other techniques, demonstration/return demonstration with models and skills practicing. Actual clinical experience was organized using an "on-call system" in which teams comprised of a trainer/mentor and two participants each were on-call for 24 hours on alternate days and provided obstetric care during that period.

Jirapa Lambussie district in Upper West Region and West Mamprusi district in Northern Region opted to use this residential training approach for their safe motherhood training. Workshops conducted under this approach included an initial two-week session where participants, accompanied by RRT members or Clinical Instructors, followed daily theoretical/lecture sessions combined with demonstrations/return demonstrations of clinical skills with evening/night clinical practice sessions or ward duties. A subsequent 1-week clinical practical training in PAC (dubbed the "PAC Attachment") was undertaken for trainees who had completed the general two-week training. This completed the cycle of 
training bringing the total period for a typical training workshop to three weeks. The content of the training documents spans all the components of safe motherhood and is essentially the same as for the SPL units.

The two districts selected the participants (referred to as "learners" or "trainees") to undergo safe motherhood training by the traditional approach. Twenty learners were to be recruited in each district, but only 15 could be recruited in West Mamprusi. Normally, a batch of 10 learners participates in each residential training session and therefore it was anticipated that 20 learners could be trained in two sessions for each district. However, to avoid nonavailability of services whilst so many midwives were engaged away from their service areas in a workshop, the programme was designed to include learners in batches of five. Hence trainees from Jirapa-Lambussie proceeded to the workshop in 4 batches, whilst those in West Mamprusi had 3 batches. The GHS decided to provide an additional five trainees from other districts to participate in each training batch, as an economic use of resources. Thus, the typical number of trainees present at any residential training workshop session was still 10, 5 from the study districts and 5 from other districts.

Training began for Jirapa-Lambussie District in May 2002 and was completed by March 2003; the PAC attachment component, however, ended in June 2003. In West Mamprusi District, training began in June 2002 and was completed by January 2003, with the PAC attachment training being concluded in August 2003.

\section{Self-Paced Learning in Safe Motherhood}

The development and implementation of the SPL approach was a collaborative process between PRIME II, the Reproductive and Child Health Unit and the Health Education Unit of the Ghana Health Service, and other in-country partners. In addition to the lessons learned during the pilot project described above, the approach builds upon lessons learned following implementation of the three-week residential Safe Motherhood course being used in Ghana, and applies principles of learning theory and sound instructional design practice to ensure that service providers acquire the knowledge and develop the clinical skills they need to provide quality Safe Motherhood services, focusing on PAC/LSS/FP. The design and development of this SPL approach have benefited from experience with alternative designs for LSS (e.g., in Indonesia and Ethiopia), PRIME/INTRAH's experience with alternative training approaches (self-directed learning and distance learning), and the experiences of other agencies such as JHPIEGO (on-the-job training for PAC).

The SPL approach responds to problems identified during evaluation of the three-week residential course including:

- Length, cost and organization of the residential course

- Insufficient opportunities for trainees to practice and become proficient in Safe Motherhood skills, especially Life Saving Skills (LSS) and Postabortion Care (PAC), because of insufficient case load at regional training sites

Additionally, the SPL approach combines the following components: self-directed learning; effective facilitation and a learner support system; opportunities for learners to practice, receive feedback, and become proficient in Safe Motherhood skills; supportive supervision to ensure providers' application and retention of skills on the job; and follow up by the Regional Resource Teams (RRTs). The training content is essentially the same as the three-week residential training course and is organized in six units made up of the following: 
- Foundations

- Providing quality antenatal care

- Providing quality care during normal labour and delivery

- Complications of labour

- Providing quality postabortion care

- Providing quality postpartum and newborn care.

For the purposes of this study, one of the two districts in each region in which PRIME II works with the GHS for safe motherhood skills training opted to use this new SPL training approach for its safe motherhood training: Nadowli in Upper West Region and Yendi in Northern Region.

In each of the selected districts, 20 providers were trained by this innovative approach. The learners attended introductory group-based foundation training in groups of 10, where the RRTs oriented them to the Self-Paced Learning approach, and took them through topics of crosscutting issues including infection prevention, problem solving, management of emergencies and referrals and client-provider interaction. At the close of this orientation, learners were paired and selected Self-Paced Learning units that they were expected to read at times convenient for them. The pairs were also expected to support each other in understanding the content, do the case studies and exercises in the selected unit, and meet with their assigned RRTs at agreed intervals. At the time of choosing a unit, learners had to complete a pre-unit questionnaire to enable the assigned trainer/facilitator to identify their potential areas of weakness and provide guidance for tackling the unit.

When the learner(s) had completed the reading of an SPL Unit, they would notify the assigned trainer who administered a post-unit questionnaire to assess the readiness of the learner(s) to undertake the practical component of the training. The experience in both the Northern and the Upper West regions was that learners proceeded generally by pairs, citing convenience for themselves and their trainers as the reason. Upon successful completion of the theoretical components of the training, the learner pairs proceeded to the Regional Training site to practice these skills on models/dolls, and were assessed using checklists designed for the purpose, before going on to complete the training with clinical practice under the coaching of RRTs and Clinical Instructors. The learners then took a post-unit test and were "checked off" by the RRT if they attained a certifying score of 80 percent or better. It had originally been required that a learner meet this cut-off score before proceeding to a subsequent unit, but this requirement raised programmatic issues that met with disapproval from the GHS. Consequently, learners moved on to a new unit irrespective of their score in the post-unit test, but later re-took an alternate post-unit test (designed by Prime II) if they had not made the cut-off score. Practically all the learners who took the alternative test achieved the cut-off score at the second attempt.

The SPL approach was implemented in a slightly different way in each district. For example, although the Northern Region followed the recommendation that the RRT members specialise in certain SPL units and be responsible for training the whole cohort in these units, the Upper West RRT assigned a pair of learners per trainer who then facilitated their training in all the units. Problems in not having skilled trainers in PAC at the onset, in both regions, resulted in having the PAC component of training as the final unit for all the learners. 
Implementation of the SPL training programme began in March 2002 in the Northern Region and a month later in the Upper West. Notwithstanding social upheavals occasioned by a chieftaincy conflict, and a subsequent declaration of a state of emergency in the Northern Region, the programme was completed there in January 2003, thereby achieving the estimated 6-9 month duration. In the Upper West Region, however, the programme was not concluded until May 2003. The learners had completed all except the PAC unit by January 2003. However, because of low caseloads the learners had to be taken in groups of $3-4$ to another training site in the Upper East Region to complete the practical component of the PAC unit, which could not be done until January-May 2003.

\section{Performance Improvement}

The Performance Improvement Approach, pioneered by PRIME II and used by USAID and many of its collaborating agencies, is a step-by-step process to find out what is needed for good performance and to provide interventions to meet those needs. PRIME II assisted the GHS and other stakeholders in defining the desired performance for the RRT and SM service providers, identifying performance gaps and their root causes, and selecting appropriate training and non-training interventions.

Interventions put in place for RRTs were the development and dissemination of clear job descriptions, provision of training and reference materials, development of supervisory and support system for RRTs to function, and training of RRTs in clinical skills, training methodology and supportive supervision. Service providers were targeted with interventions such as the provision of supplies and equipment, provision of reference materials, training in safe motherhood clinical and health education skills, and strengthening of management information systems.

Selected performance improvement interventions were implemented simultaneously across both study groups in two districts per region by PRIME II and other stakeholders. As illustrated in the diagram below, such improvements are expected to increase access to quality SM services and to improve client health outcomes.

\section{Framework for Assessing Reproductive Health Outcomes}
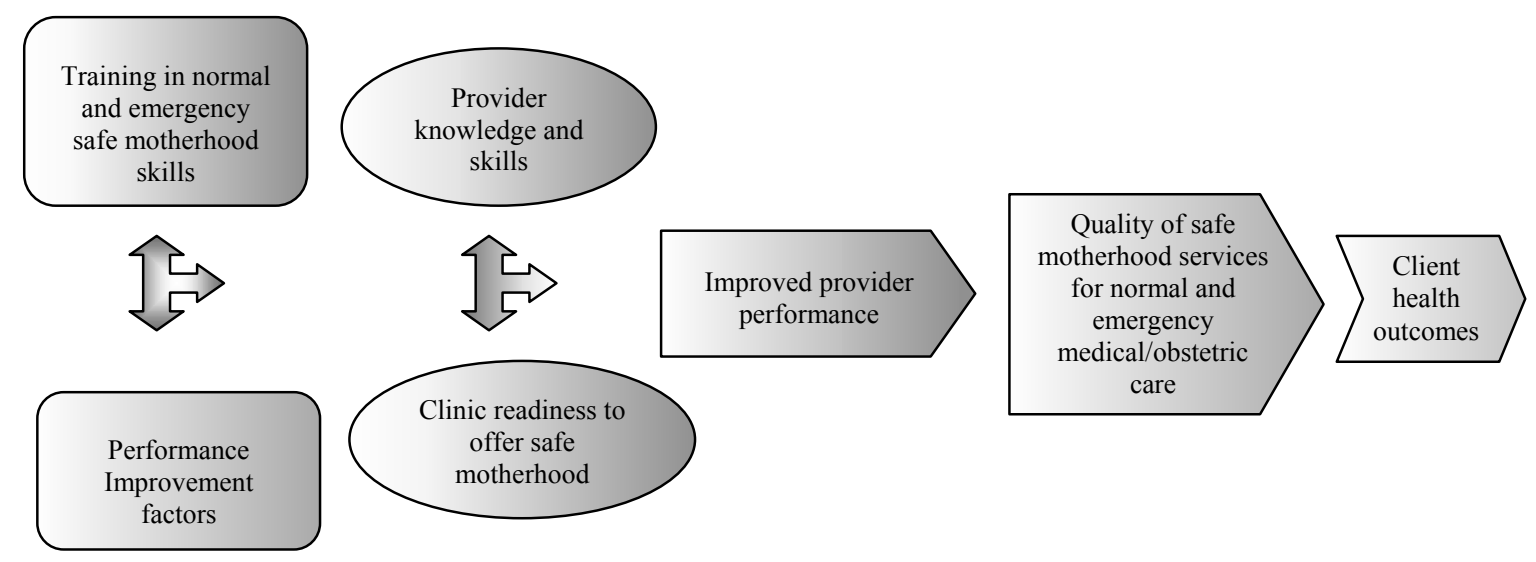


\section{Research Methodology}

A non-randomised pre-intervention post-intervention comparison group design was used. The intervention group consisted of those clinics and district hospitals in the two districts in which the SPL approach was introduced (i.e., six health centres in Yendi District and 13 health centres in Nadowli District, and one district hospital in each). The comparison group consisted of those clinics and district hospitals in the two districts in which the residential approach was introduced (i.e., three health centres in West Mamprusi district, 12 health centres in Jirapa Lambussie district and one district hospital in each). The effect of the interventions on the key dependent variables (such as quality of services, client health and medical outcomes) was measured six months after completion of the interventions to enable the interventions to settle in and function smoothly.

\begin{tabular}{|l|c|c|c|}
\hline Time: & Baseline & Intervention & Endline \\
\hline Intervention districts & $\mathrm{O}_{1}$ & $\mathrm{X}_{1}$ & $\mathrm{O}_{2}$ \\
\hline Comparison districts & $\mathrm{O}_{3}$ & $\mathrm{X}_{2}$ & $\mathrm{O}_{4}$ \\
\hline
\end{tabular}

Where:

$\mathrm{X}_{1}=\quad \mathrm{SPL}$ training programme and other Performance Improvement interventions

$\mathrm{X}_{2}=$ Residential training course and other Performance Improvement interventions

$\mathrm{O}_{1} \& \mathrm{O}_{3}=\quad$ Baseline measures of provider knowledge and skills, clinic readiness, quality of services, and client heath and medical outcomes

$\mathrm{O}_{2} \& \mathrm{O}_{4}=\quad$ Endline measures of provider knowledge and skills, clinic readiness, quality of services, and client health and medical outcomes

\section{Data collection process and analysis}

Data collection tools: The HRU and FRONTIERS collaborated with other stakeholders to develop five study data collection instruments:

1) Inventory of commodities available and services provided at the service delivery unit;

2) Observation guide for interaction between ANC clients and service providers as well as PAC patients;

3) Observation guide for labour and delivery;

4) Exit interview questionnaire for $\mathrm{ANC}$ and PAC clients;

5) Interview questionnaire for staff providing safe motherhood services at the service delivery point.

These instruments were used to: a) take a complete inventory of equipment and supplies at each service delivery site; b) record service statistics (where available) for the previous 12 months; c) interview and test all providers trained at each site to gauge their knowledge of safe motherhood services; d) observe interactions between service providers and new and 
continuing safe motherhood clients; and e) interview ANC and PAC clients after observation before they left the facility.

Instruments were also designed to collect financial expenditures for the various activities during the implementation of each training approach in the two regions, and to measure opportunity costs related to staff time required for each approach (see appendix 1). The cost assessment instruments included:

- SPL learner time tracking form

- Questionnaire for Regional and District Health Management Team (RHMT/DHMT) members

- Questionnaire for Regional Resource Teams (RRTs)

- Questionnaire for Clinical Instructors

- Expense forms to record Travel and Transportation (T\&T) and per diem payments to SPL and Traditional learners, RRTs, RHMT/DHMT members, resource persons and others.

Field work: Experienced midwives from the two regions, but who did not live in the study districts, were selected, orientated to the project, and trained to administer the data collection instruments at baseline and endline. At baseline, a complete list of the 40 functional facilities in the study sites was developed and fieldwork teams were formed. However, two facilities (Janga in the West Mamprusi district and Church of Christ in Yendi) were dropped in the Northern Region because they were not functional at the time of data collection, giving a total of 38 facilities visited.

At baseline, observations of regular deliveries and emergencies, as well as PAC, were limited to the four district hospitals due to the low caseload. During the baseline survey, 12 interviewers covered the four hospitals on 8-hour shifts for four weeks to try to capture all emergency cases and to observe possible variations in service quality between night and day shifts. Given the extremely small number of cases observed during the baseline, concerns were raised about the value of this 24-hour observation. Following discussions among all stakeholders it was agreed that, for the endline survey, direct observation of labour and delivery and PAC be replaced with observation of simulated situations. The observation of simulated cases was extended to cover both hospitals and health centres, and a two-member team of national level safe motherhood clinical instructors undertook these assessments.

At the health centres, one person conducted interviews, the facility inventory and ANC observations; each health centre was visited for one week during both baseline and endline surveys. The data collectors met with their supervisors to review the tools for completeness and accuracy in the field. The Study Coordinator spent two additional weeks to closely monitor the initial fieldwork and assist in harmonizing data collection by visiting all interviewers in the two study regions. At the end of the fieldwork, the study coordinator met with the supervisors for a wrap-up meeting. Field notes were prepared and compiled in separate field reports. The duration for both baseline and endline surveys was approximately one month.

In collecting financial cost data, the regions submitted all expenditure reports on personnel travel and transport, per diem, hiring of conference room, stationery, fuel, allowances for resource persons and supplies for training. A pre-designed tool was used by which any payments made to both learners and resource persons were signed and submitted to the Health Research Unit, Ghana Health Service. Receipts for supplies, fuel, stationery, 
photocopies, communication and other expenditures were also collected, submitted and analysed for accuracy and completeness. For opportunity costs, the time required by personnel for each set of activities related to the two approaches was recorded.

Data processing and analysis: The completed instruments were processed at the HRU data processing unit using Epi Info software. The data were analysed using SPSS, and basic tables and graphics were prepared. Group mean scores were calculated by summing individual scores and dividing them by total number of group members, and these were then compared across the two approaches.

To classify provider performance as acceptable or unacceptable, the basic knowledge and skills required for professional practice were measured and compared with the minimum level of performance needed for a person to be considered professionally competent. The "cut-off score" was set on performance assessment ratings: how many or what percent of the total number of job-related behaviours listed in the job performance assessment instrument must be checked "Yes" for the person being rated to be considered minimally competent. The numerical score achieved was related to the possible total score in order to arrive at the percentage. Drawing from PRIME II's experience in other countries, the research team set this score at 70 percent.

Data from the time tracking sheets for SPL learners were entered using Excel and summaries made per learner for each unit (with the exception of the foundations unit, which was a sixday classroom-based activity). The foundations unit was treated as a uniform amount of time for all SPL Learners, including their travel time. Data on time for RRTs, Clinical Instructors, RHA and DHA staff were doubly entered using the EPI INFO soft ware. The data were then imported from EPI INFO into Excel and summarized.

\section{Sample Characteristics}

\section{Facilities visited}

A total of 38 public facilities were visited in the two study regions for both the baseline and endline surveys, made up of 34 health centres and 4 district hospitals. Twenty-one of these facilities were in the intervention districts and 17 in the comparison districts (see Table 1).

Table 1: Number of facilities visited by type

\begin{tabular}{|c|c|c|c|c|c|c|}
\hline Characteristics & \multicolumn{2}{|c|}{ Northern Region $(\mathrm{n}=11)$} & \multicolumn{2}{c|}{ Upper West $(\mathrm{n}=27)$} & \multicolumn{2}{c|}{ All facilities $(\mathrm{n}=38)$} \\
\hline & Intervention & Comparison & Intervention & Comparison & Intervention & Comparison \\
\hline Health Centre & 6 & 3 & 13 & 12 & 19 & 15 \\
\hline Hospital & 1 & 1 & 1 & 1 & 2 & 2 \\
\hline
\end{tabular}




\section{Staff interviewed}

Staff interviewed included those who were on duty in the maternity units of the facilities visited during the period of the study: 40 in the intervention and 37 in the comparison groups for the baseline survey. The endline focused on staff in the maternity units/areas of hospitals and health centres, which had participated in the training interventions. Table 2 shows selected socio-demographic characteristics of staff interviewed. The age range and mean for staff in both intervention and comparison districts were similar at baseline and endline as indicated in Table 2. Generally, staff in the maternity units was mostly made up of nurses and midwives. The majority of the staff members in both study groups was married.

Table 2: Characteristics of staff interviewed by type of training intervention

\begin{tabular}{|l|c|c|c|c|}
\hline \multirow{2}{*}{ Characteristic } & \multicolumn{2}{|l|}{ Intervention } & \multicolumn{2}{l|}{ Comparison } \\
\cline { 2 - 5 } & $\begin{array}{c}\text { Baseline } \\
(\mathrm{n}=40)\end{array}$ & $\begin{array}{c}\text { Endline } \\
(\mathrm{n}=36)\end{array}$ & $\begin{array}{c}\text { Baseline } \\
(\mathrm{n}=37)\end{array}$ & $\begin{array}{c}\text { Endline } \\
(\mathrm{n}=24)\end{array}$ \\
\hline Mean age & 45 & 43 & 45 & 46 \\
$($ Range $)$ yrs & $(26-59)$ & $(36-58)$ & $(28-53)$ & $(38-59)$ \\
\hline Type of Staff & 7 & 3 & 1 & 2 \\
Nurse & 33 & 32 & 33 & 22 \\
Nurse midwife & 0 & 1 & 3 & 0 \\
Other & 31 & 28 & 29 & 18 \\
\hline Marital Status & 2 & 3 & 1 & 2 \\
Married & 1 & 3 & 5 & 3 \\
Single & 6 & 2 & 2 & 1 \\
Widow & & & & \\
Divorced/separated & & 3 & 29 \\
\hline
\end{tabular}

\section{Clients observed}

Observations of client-provider interactions were made during ANC sessions and during labour and delivery, as well as during management of postabortion care patients in both study groups as illustrated in Table 3; 498 and 363 interactions were observed at baseline and endline respectively. The labour and delivery as well as PAC observations at baseline were carried out in the four study hospitals; the health centres were excluded because of low caseloads. However, at endline, provider skills in labour, delivery and PAC were assessed by observing their performance in simulated situations for both hospitals and health centres in all study groups because the sample sizes for the baseline were too small to allow meaningful comparisons between the groups and over time. 
Table 3: Number of cases observed (baseline) or simulated (endline)

\begin{tabular}{|l|c|c|c|c|}
\hline \multirow{2}{*}{ Type of service } & \multicolumn{2}{|c|}{ Intervention } & \multicolumn{2}{c|}{ Comparison } \\
\cline { 2 - 5 } & Baseline & Endline & Baseline & Endline \\
\hline ANC & 270 & 228 & 228 & 135 \\
\hline Labour and delivery* & 17 & 36 & 45 & 24 \\
\hline Postabortion care* & 4 & 29 & 6 & 18 \\
\hline
\end{tabular}

*Endline figures represent number of providers who participated in skill assessment with case simulations, whilst baseline figures represent actual cases observed.

\section{Clients interviewed}

All ANC clients observed at baseline and endline were also interviewed. Most of ANC clients in both study groups at baseline and endline were Dargartis, did not have any formal education, were Christians and were married. Table 4 shows selected socio-demographic characteristics of ANC clients interviewed. There are no statistically significant differences between the samples, both pre-post and intervention-comparison, with respect to sociodemographic characteristics.

Table 4: Characteristics of ANC clients interviewed

\begin{tabular}{|l|c|c|c|c|}
\hline \multirow{2}{*}{ Characteristics } & \multicolumn{2}{|c|}{ Intervention } & \multicolumn{2}{c|}{ Comparison } \\
\cline { 2 - 5 } & $\begin{array}{c}\text { Baseline } \\
(\mathrm{n}=270)\end{array}$ & $\begin{array}{c}\text { Endline } \\
(\mathrm{n}=228)\end{array}$ & $\begin{array}{c}\text { Baseline } \\
(\mathrm{n}=228)\end{array}$ & $\begin{array}{c}\text { Endline } \\
(\mathrm{n}=135)\end{array}$ \\
\hline Mean years & 27 & 27 & 28 & 26 \\
\hline Range (minimum-maximum) & $15-50$ & $15-45$ & $15-47$ & $15-44$ \\
\hline Marital status & $\%$ & $\%$ & $\%$ & $\%$ \\
\hline Married monogamous & 62 & 64 & 65 & 64 \\
Married polygamous & 34 & 32 & 29 & 29 \\
Unmarried, cohabiting & 3 & 1 & 3 & 6 \\
Unmarried, no partner & 2 & 1 & 2 & 1 \\
\hline Level of Education & $\%$ & $\%$ & $\%$ & $\%$ \\
\hline None & 80 & 72 & 69 & 70 \\
Primary & 15 & 20 & 24 & 22 \\
Secondary & 3 & 5 & 6 & 6 \\
Tertiary & 1 & 2 & 1 & 1 \\
\hline
\end{tabular}




\begin{tabular}{ccccc}
\hline Ethnic group & $\%$ & $\%$ & $\%$ & $\%$ \\
\hline \hline Dargati & 63 & 60 & 65 & 66 \\
Dagomba & 19 & 22 & 1 & 0 \\
Mamprusi & 0 & 1 & 19 & 20 \\
Sissala & 2 & 4 & 8 & 11 \\
Other & 17 & 13 & 8 & 3 \\
\hline Religion & $\%$ & $\%$ & $\%$ & $\%$ \\
\hline \hline Christian & 51 & 50 & 56 & 47 \\
Muslim & 29 & 36 & 16 & 19 \\
Traditional & 19 & 11 & 27 & 32 \\
Other & 1 & 2 & 1 & 2 \\
\hline \hline
\end{tabular}

\section{Cost analysis}

Due to the small numbers of learners and resource persons, data were collected from all participants in the study. For learners in the intervention group, the total of 40 in the two regions had their time tracked. With RRTs, Clinical Instructors, RHA and DHA-member participants in the study, only those who were available during the data collection period were interviewed. Table 5 below shows the numbers of respondents from whom data were collected for each region.

Table 5: Category of personnel interviewed for the cost analysis at endline

\begin{tabular}{|l|c|c|c|c|}
\hline \multirow{2}{*}{$\begin{array}{l}\text { Personnel } \\
\text { Category }\end{array}$} & \multicolumn{2}{|c|}{ Intervention } & \multicolumn{2}{c|}{ Comparison* $^{*}$} \\
\cline { 2 - 5 } & Northern & Upper West & Northern & Upper West \\
\hline Learners & 20 & 20 & 30 & 40 \\
\hline RRTs & 10 & 10 & 10 & 10 \\
\hline Clinical Instructors & 5 & 4 & 6 & 6 \\
\hline RHA/DHA/ Other & 5 & 4 & 6 & 9 \\
\hline
\end{tabular}

* The number of learners for the Traditional approach includes learners from other districts added to maintain the usual size of batches (10) and make the most efficient use of RRTs and other learner support staff. The cost of these additional learners has also been factored into the calculation of average costs. However, the OR results evaluation was limited to a smaller sample of Traditional learners as per the original sampling design. 


\section{RESULTS}

\section{Clinic readiness to offer safe motherhood services}

Having staff trained and competent in safe motherhood skills is insufficient to improve the quality of safe motherhood services offered by GHS facilities. The overall clinic environment needs to be ready to offer minimum quality services for normal situations, as well as emergency obstetrical care. The definition of 'clinic readiness' depends on the level of facility under consideration and the range of safe motherhood services it is expected to provide. The GHS has defined the types of safe motherhood services that should be available at each level in the 'National Reproductive Health Policy and Standards' document and so the indicators of readiness are defined for each level separately according to the following broad categories: availability of equipment and supplies, medicines, reference materials/books, registers, client record forms, IEC materials, supervisory and management systems. These indicators were measured through the inventory checklist.

\section{Environment and Tools}

\section{Physical Infrastructure}

The hospitals in both study groups had adequate physical infrastructure, whereas the health centres had lower levels of readiness. Infrastructure was assessed in terms of availability of storage for drugs and supplies (including a refrigerator for vaccines), adequacy of rooms for ANC and labour, water supply and sterilizing equipment. Four at baseline and three at endline in the intervention group did not have storage areas for drugs and supplies. At baseline, six out of 21 intervention facilities and two out of 17 comparison facilities did not have refrigerators, but by endline, only two facilities in the comparison group did not have refrigerators.

All facilities visited had at least one ANC room with a window. Although six facilities in both study groups did not have sufficient light to see the clients at baseline, only three in each group lacked sufficient light at endline. Availability of running tap water did not change since baseline, with about two-thirds of the facilities in both groups not having running water, although they did have other sources of water, such as boreholes and wells. Three out of the four hospitals use autoclaves and hot air sterilizers, and 25 health centres and 2 hospitals boiled the instruments, with little change by endline.

\section{Equipment, Supplies, and Medications}

The National Reproductive Health Service Policy and Standards has indicated the basic equipment required for providing Safe Motherhood services at each level of service delivery. Based on these standards, the hospitals were fairly well equipped, although a few items were missing - one of the two hospitals in the comparison group had all items except oxygen for resuscitation, both hospitals in the comparison group did not have kits for urine and haemoglobin testing, and one hospital did not have a sterilizer, manual vacuum aspirator or IUD kits.

Overall, most of the health centres were not equipped to the expected standard. Fourteen health centres in each study group did not have urine-testing kits, and two-thirds in both groups did not have sterilizers or sterile dressing material. Other items missing were 
catheters, delivery sets, IV cannulae, partograph, oxygen for resuscitation, vacuum extraction apparatus, and Norplant implants, as shown in Table 6.

Table 6: Number of health centres lacking selected equipment and supplies

\begin{tabular}{|c|c|c|c|c|}
\hline \multirow{2}{*}{ Type of Equipment } & \multicolumn{2}{|c|}{$\begin{array}{l}\text { Intervention } \\
\qquad(\mathrm{N}=19)\end{array}$} & \multicolumn{2}{|c|}{$\begin{array}{l}\text { Comparison } \\
\qquad(\mathrm{N}=15)\end{array}$} \\
\hline & $\begin{array}{l}\text { Baseline } \\
(n=19)\end{array}$ & $\begin{array}{l}\text { Endline } \\
(n=19)\end{array}$ & $\begin{array}{l}\text { Baseline } \\
(\mathrm{N}=15)\end{array}$ & $\begin{array}{l}\text { Endline } \\
(n=15)\end{array}$ \\
\hline $\begin{array}{l}\text { Oxygen tank, tubing, and face } \\
\text { mask or nasal canula }\end{array}$ & 19 & 19 & 14 & 15 \\
\hline Sterile sanitary pads & 18 & 17 & 15 & 14 \\
\hline Norplant kit & 17 & 18 & 14 & 13 \\
\hline $\begin{array}{l}\text { Angle poised light or torch } \\
\text { light }\end{array}$ & 16 & 13 & 15 & 9 \\
\hline $\begin{array}{l}\text { Straight metal urethral } \\
\text { catheter }\end{array}$ & 16 & 19 & 11 & 12 \\
\hline Vacuum extraction apparatus & 16 & 12 & 15 & 15 \\
\hline IV cannulae & 15 & 12 & 12 & 10 \\
\hline Sterile gauze pads or swabs & 15 & 8 & 13 & 4 \\
\hline Sterilizer & 15 & 14 & 11 & 11 \\
\hline Partographs & 14 & 4 & 8 & 3 \\
\hline Urine testing kit & 14 & 18 & 14 & 15 \\
\hline IUD kit & 13 & 12 & 10 & 10 \\
\hline Antenatal forms & 11 & 5 & 5 & 0 \\
\hline $\begin{array}{l}\text { Bulb syringe for suctioning } \\
\text { infant }\end{array}$ & 8 & 0 & 8 & 3 \\
\hline Delivery set & 8 & 3 & 6 & 3 \\
\hline IV fluid giving sets & 4 & 2 & 3 & 1 \\
\hline
\end{tabular}

Availability of medication was assessed in terms of at least one drug in the following groups: anti-allergics, anti-diabetics, anti-malarial, eclampsia, family planning, immunization, antibiotics, parenteral fluids, labour management, analgesics, vitamins and disinfectants. Generally, hospitals were well stocked with medication for safe motherhood services except for insulin, which was missing in three hospitals. With the exception of anti-diabetic drugs, all health centres had at least one drug in all groups. The IUD and Norplant implants were missing in most centres. There were considerable improvements over time in the availability of some items, such as delivery sets, bulb syringes and partographs in both study groups. 


\section{Staffing}

Staffing in the facilities visited reflected the GHS staffing guidelines in terms of category of personnel and type of facility at both baseline and endline. Obstetrician/Gynaecologists, physicians, pharmacists and anaesthetists were only found in the hospitals. Nurses and midwives represented the majority of the personnel in the maternity units in both intervention and comparison sites. All the personnel were female, except for a few male Medical Assistants, physicians and Obstetrician/Gynaecologist specialists.

\section{Management Information Tools, IEC and reference materials}

All facilities had registers for ANC, delivery and FP. However, most information was recorded on the client cards, and therefore the registers were only partially completed. Some information, such as anthropometrical measurements and laboratory investigations, were missing in the registers. Only two facilities in the intervention group and three in the comparison group had PAC registers. All the facilities had basic safe motherhood records covering the period 2001 and 2002.

Information, Education and Communication (IEC) is an integral part of the National Reproductive Health Service Policy and Standards. As indicated in Table 7, there was a marked improvement in the availability of IEC materials by the endline for both groups. However, as many as 6 out of the 21 facilities in the intervention group still did not have clinical management protocols and guidelines at the endline.

Table 7: Availability of IEC material in the facilities (Hospitals and Health Centres)

\begin{tabular}{|l|c|c|c|c|}
\hline \multirow{2}{*}{ Items } & \multicolumn{2}{|c|}{ Intervention } & \multicolumn{2}{c|}{ Comparison } \\
\cline { 2 - 5 } & Baseline & Endline & Baseline & Endline \\
\hline $\begin{array}{l}\text { Educational materials on warning signs of } \\
\text { pregnancy }\end{array}$ & 6 & 18 & 9 & 15 \\
\hline Clinical management protocols guidelines & 10 & 15 & 12 & 16 \\
\hline $\begin{array}{l}\text { Educational materials on sexually transmitted } \\
\text { diseases and/or HIVIAIDS }\end{array}$ & 12 & 19 & 14 & 15 \\
\hline $\begin{array}{l}\text { Educational materials on postpartum } \\
\text { care/newborn care/breastfeeding }\end{array}$ & 15 & 19 & 12 & 16 \\
\hline Educational materials on family planning & 17 & 21 & 16 & 17 \\
\hline
\end{tabular}

\section{Transport for Emergency Services}

Transport for emergency services remains inadequate at the facilities. Even though patients have access to alternate means in the communities, it can take up to 24 hours for the transfer to be effected. A transport system or ambulance for referral of emergency services was available in 5 out of the 21 intervention facilities and 3 out of the 17 comparison facilities at baseline. Two more facilities had subsequently acquired ambulances in the intervention group. However, patients can reach a referral site by other means such as car, motorbike and bicycles. The study also showed that a referred woman waits for between 20 minutes to 2 
hours in a hospital, and up to 24 hours in a health centre, before she leaves the facility for transfer to a referral site.

\section{Job expectations}

In order to perform well, staff need clear job expectations that are aligned with organizational goals. Typically, these job expectations can come from a variety of sources - national standards, organizational policies, well-written job descriptions, a supervisor or clinic director, a team leader, colleagues, clients and the community.

The MOH, in its National Reproductive Health Service Policy and Standards, provides a set of basic expectations and minimum acceptable levels of service provision for each component of reproductive health. In providing safe motherhood services, providers are expected to meet the objectives of ANC, labour and delivery and PNC services as stated in the document, namely to:

- $\quad$ Promote and maintain the physical, mental and social health of mother and baby

- Detect and treat high risk conditions arising during pregnancy

- Ensure delivery of full term healthy baby with minimal stress or injury to mother and baby

- Help prepare mother to breast feed successfully, experience normal puerperium and take good care of child physically, psychologically and socially

- Ensure proper management of the four stages of labour

- Ensure early identification, proper management, treatment and referral of complications during labour and postnatal period.

When interviewed, providers indicated diverse expectations of their job. They consider preventing maternal and infant mortality as their main task through ensuring safe delivery of both mother and child, and this increased from 69 percent to 98 percent by the endline. Ensuring good ANC to prevent and detect complications during pregnancy also increased from 26 percent to 38 percent at endline. Other expectations mentioned include: infection prevention, ensuring client satisfaction and maintaining confidentiality, postnatal care including breastfeeding, and provision of immunization for both mother and child.

These diverse expectations could be explained by the lack of clear job descriptions and guidance for providers at their facilities at the baseline, when only 32 percent of staff interviewed in hospitals and 17 percent in health centres could produce evidence of their job description. More than half the providers claimed that the Reproductive Health Policy and Standards (2000) was not available in their facilities. By the endline, however, more providers $(56 \%)$ had written job descriptions in the intervention group than the comparison group (25\%). Similarly, two-thirds of providers in both groups stated that they had the Reproductive Health Policy and Standards in their facilities at the endline.

\section{Performance feedback}

'Performance feedback' refers to the information given to a person describing the quality of their work. Sources of performance feedback can be a supervisor, colleague, community or self. Performance feedback should be provided in a clear, timely, descriptive and direct manner. Good feedback is given immediately during supervision and is followed by a written note. 
Feedback, at both baseline and endline in both study groups, was perceived by the majority of providers to be too infrequent. About half of the providers in both study groups stated that they had received feedback in the last six months prior to the interview at baseline and endline. Twenty-four out of thirty-seven providers at baseline and twenty-two out of thirty at endline indicated that feedback was mostly given verbally, immediately during supervision (41\% at baseline and $60 \%$ endline) and sometimes during staff meetings. Feedback was most often given by the DHMT. Facility in-charges, clients, regional program coordinators, colleagues, RRT and community members also occasionally gave feedback.

\section{Motivation}

Providers are expected to perform up to specified standards, but they need motivation to do so. Motivation can include people receiving recognition from their supervisors for their work in several forms: words of appreciation, recognition in front of colleagues or the public, small tokens, and small rewards. Recognition for good performance is not given very often. A little less than half of providers at baseline and endline stated that they had ever received any recognition for their work; more providers in the health centres than the hospitals had received recognition in the last year. This included certificates, cash awards and small parcels. Recognition for awards was most often done by the DHMT but the criteria were not well known. Sanctions for poor performance were a rare occurrence - only two providers indicated that they had ever been sanctioned in both surveys, in the form of reprimands or insults, sometimes in the presence of patients or their relatives.

\section{Knowledge and skills}

Both training approaches were intended to improve the theoretical knowledge and practical skills of providers in a range of safe motherhood services for both normal and risk conditions in pregnancies, and during labour and deliveries. Provider knowledge on ANC and labour and delivery was assessed through in-depth interviews.

\section{Antenatal Care}

Knowledge about antenatal care was assessed by asking questions about: activities carried out during first and subsequent ANC visits, comprehensive medical history, general physical, abdominal and vaginal examinations, laboratory tests, routine medication and education of clients.

There were some slight improvements in the individual knowledge indicators in both groups, with the intervention group performing slightly better. It is important to note, however, that there was a statistically significant improvement in only one indicator (knowledge of vaginal $\left.\operatorname{exam}^{1}\right)$; moreover, this was the lowest scoring indicator for both groups at both baseline and endline.

A comparison of the differences in ANC knowledge between the two groups over time is presented visually in Figure 2, in the form of box plots ${ }^{2}$. The boxes represent the distribution

\footnotetext{
1 The vaginal examination covered the following, wearing of gloves for the examination, pregnancy confirmation, checking uterus position, checking for presence of fibromyoma and ovarian cyst, as well as vaginal discharge / bleeding and checking external genitalia for rashes/sores.

2 A box plot summarizes the range of scores for each group. A rectangular box extends vertically from the $25^{\text {th }}$ to the $75^{\text {th }}$ percentiles of the scores. The horizontal bar within the box indicates the median value. The lines extending from the box go to the most extreme values.
} 
of the group mean scores for the nine indicators in relation to a median value derived from these nine indicators. These distributions indicate that the intervention group performed better than the comparison group, having started at a lower level at baseline and ending higher at endline. Statistical testing (paired t-test) showed a significant improvement between endline and baseline for the intervention group $(\mathrm{p}<0.01)$. There was also a significant difference between the intervention and comparison groups at endline $(p<0.01)$, confirming that the intervention group performed better overall.

Figure 1: Indicators of Provider Knowledge in ANC by study group

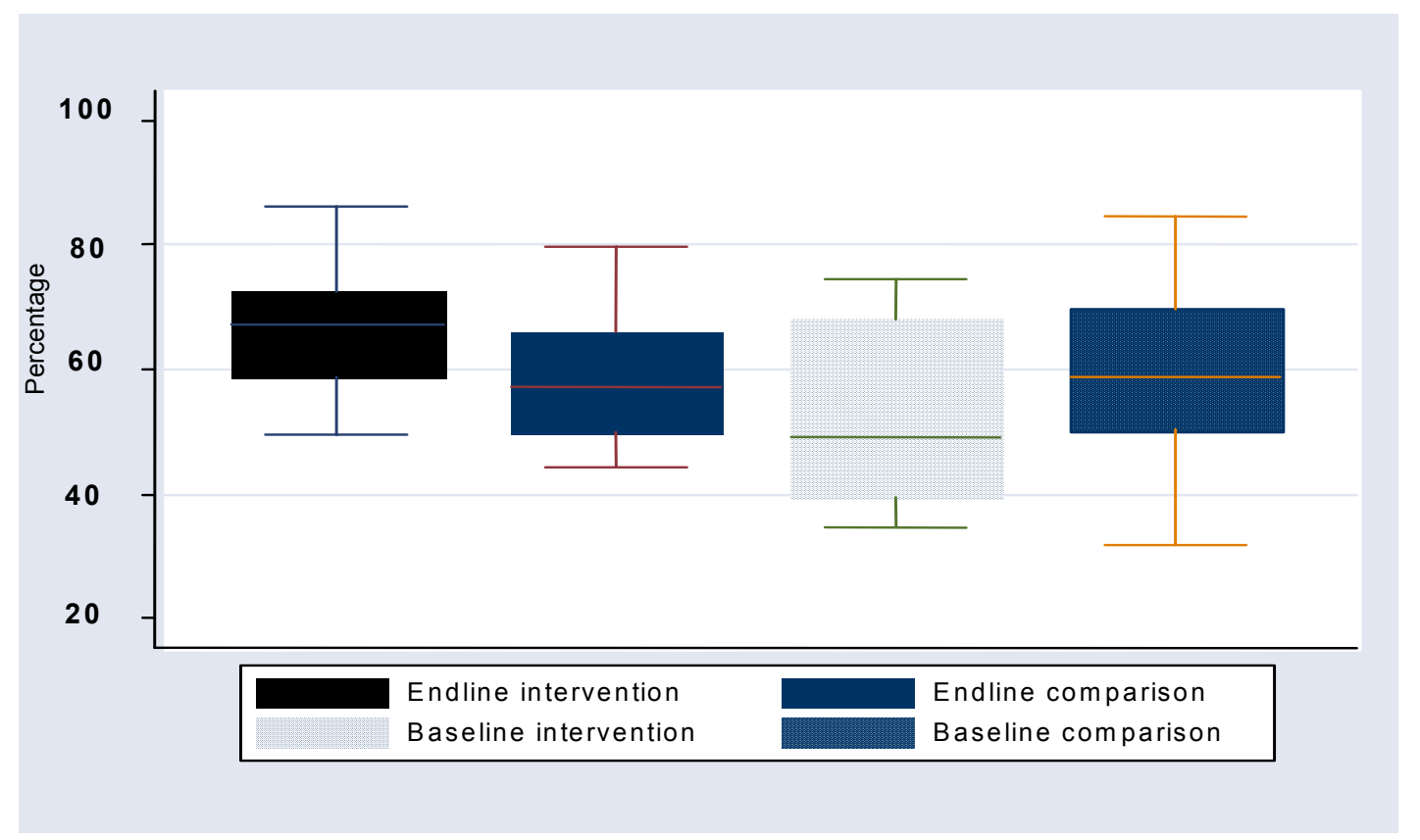

As can be seen in Table 8, by the endline the total group mean scores for all of the nine indicators were still below the cut-off score of $70 \%$ for both intervention and comparison groups. 
Table 8: Group mean score for providers' knowledge of ANC indicators

\begin{tabular}{|l|c|c|c|c|}
\hline \multirow{2}{*}{ Indicator } & \multicolumn{3}{|c|}{ Provider's Knowledge of Antenatal Care } \\
\cline { 2 - 5 } & \multicolumn{2}{|c|}{ Intervention } & \multicolumn{2}{c|}{ Comparison } \\
\cline { 2 - 5 } & $\begin{array}{c}\text { Baseline } \\
\mathrm{n}=40 \\
\%\end{array}$ & $\begin{array}{c}\text { Endline } \\
\mathrm{n}=36 \\
\%\end{array}$ & $\begin{array}{c}\text { Baseline } \\
\mathrm{n}=37 \\
\%\end{array}$ & $\begin{array}{c}\text { Endline } \\
\mathrm{n}=24 \\
\%\end{array}$ \\
\hline First antenatal care visit & 68 & 72 & 70 & 66 \\
\hline Subsequent antenatal care visit & 68 & 59 & 65 & 56 \\
\hline Comprehensive medical history & 39 & 53 & 50 & 45 \\
\hline General physical exam & 49 & 73 & 61 & 53 \\
\hline Obstetrical/abdominal exam & 74 & 86 & 84 & 80 \\
\hline Vaginal exam & 38 & $50^{* *}$ & 32 & $44^{* *}$ \\
\hline Laboratory test & 48 & 68 & 51 & 60 \\
\hline Routine medications & 69 & 86 & 85 & 74 \\
\hline Educating antenatal clients & 35 & 60 & 50 & 50 \\
\hline Total & $\mathbf{5 4}$ & $\mathbf{6 7}$ & $\mathbf{6 1}$ & $\mathbf{5 9}$ \\
\hline
\end{tabular}

$* * \mathrm{p}<0.05$

These poor levels of knowledge are reflected in Figure 2, where, except for the obstetric/abdominal examination, less than one third of providers in both groups scored 70 percent and above. More providers in the SPL group (31\%) reached the 70 percent score for provider knowledge in ANC than in the comparison group $(8 \%)$. This difference was statistically significant.

Figure 2: Providers scoring $70 \%$ and above in ANC knowledge assessment at endline

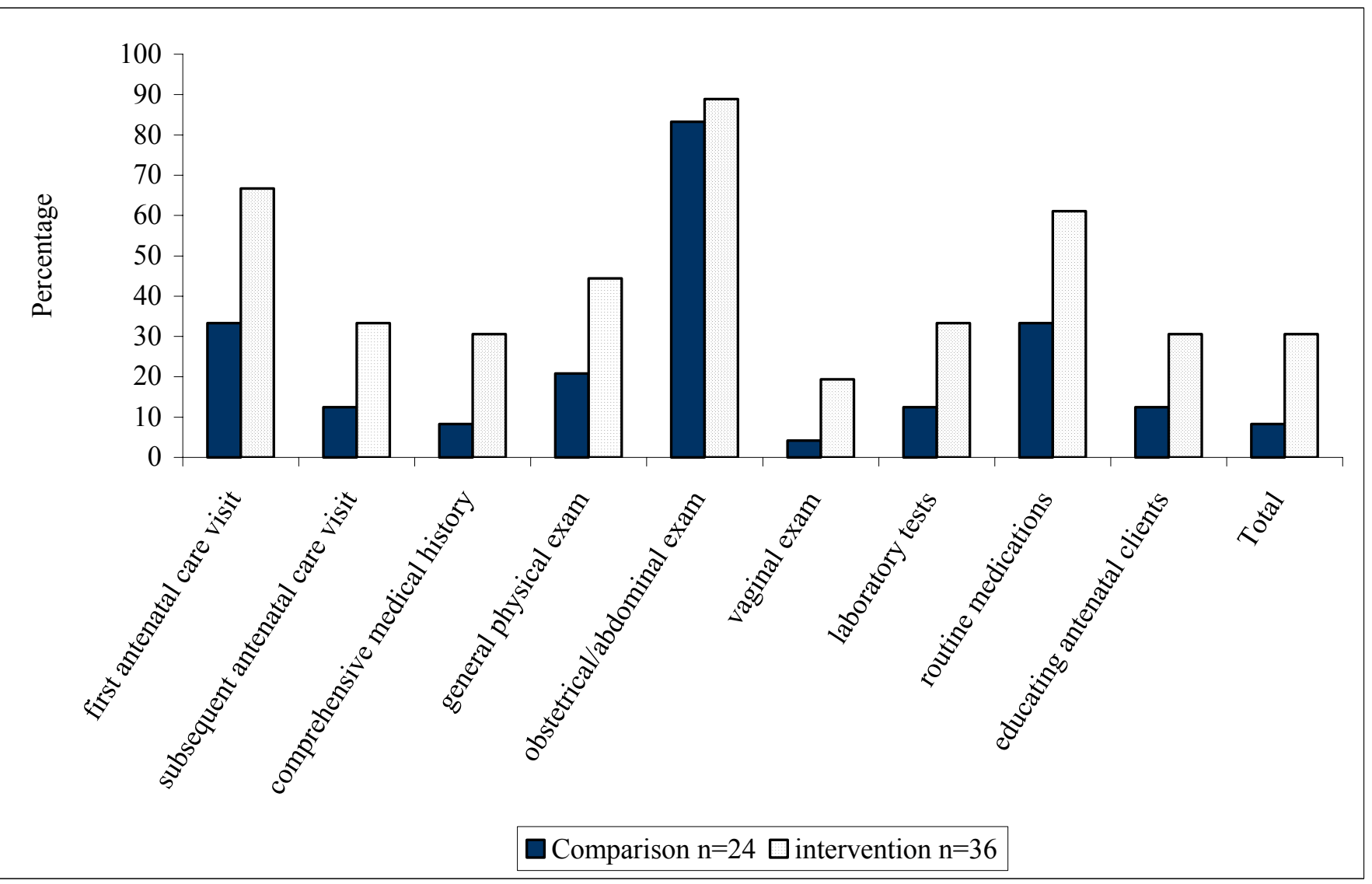




\section{Labour and delivery}

Areas assessed were activities during admission, comprehensive medical/obstetrical history, monitoring of first, second and third stages of labour and activities during the immediate post partum. Providers' knowledge was low on labour and delivery issues at baseline. At endline, only the intervention group improved, with statistically significant increases in the mean values, while the comparison group showed non-significant declines. Table 9 shows the scores for each of the composite indicators for knowledge of labour and delivery. The data suggest that knowledge levels were fairly even across these indicators, and that statistically significant improvements were found across all indicators except one for the intervention group.

The box plots (Figure 3) show these comparisons visually. The paired t-test shows a significant improvement between baseline and endline for the intervention group $(p<0.005)$, although the endline intervention group score is not significantly different from that of the comparison group. This means that the SPL approach did improve knowledge about labour and delivery, but that this increase did not raise knowledge levels above those that already existed in the comparison group (at baseline or endline).

Table 9: Group mean score for provider knowledge on labour and delivery

\begin{tabular}{|l|c|c|c|c|}
\hline \multirow{2}{*}{ Measure } & \multicolumn{3}{|c|}{ Provider's Knowledge of Labour and Delivery } \\
\cline { 2 - 5 } & \multicolumn{2}{|c|}{ Intervention } & \multicolumn{2}{c|}{ Comparison } \\
\cline { 2 - 5 } & $\begin{array}{c}\text { Baseline } \\
\mathrm{n}=40 \\
\%\end{array}$ & $\begin{array}{c}\text { Endline } \\
\mathrm{n}=36 \\
\%\end{array}$ & $\begin{array}{c}\text { Baseline } \\
\mathrm{n}=37 \\
\%\end{array}$ & $\begin{array}{c}\text { Endline } \\
\mathrm{n}=24 \\
\%\end{array}$ \\
\hline Activities at admission & 46 & $55^{*}$ & 61 & 50 \\
\hline Comprehensive medical/obs. history & 50 & 61 & 56 & 54 \\
\hline Monitoring first stage of labour & 41 & $59^{* * *}$ & 56 & 52 \\
\hline Monitoring second stage of labour & 37 & $64^{* * *}$ & 53 & 49 \\
\hline Monitoring third stage of labour & 45 & $68^{* * *}$ & 57 & 59 \\
\hline Activities immediate postpartum & 42 & $57^{* *}$ & 58 & 61 \\
\hline \multicolumn{1}{|c|}{ TOTAL } & 43 & $61^{* * *}$ & 57 & 54 \\
\hline
\end{tabular}


Figure 3: Comparison of group score of provider knowledge of labour and delivery

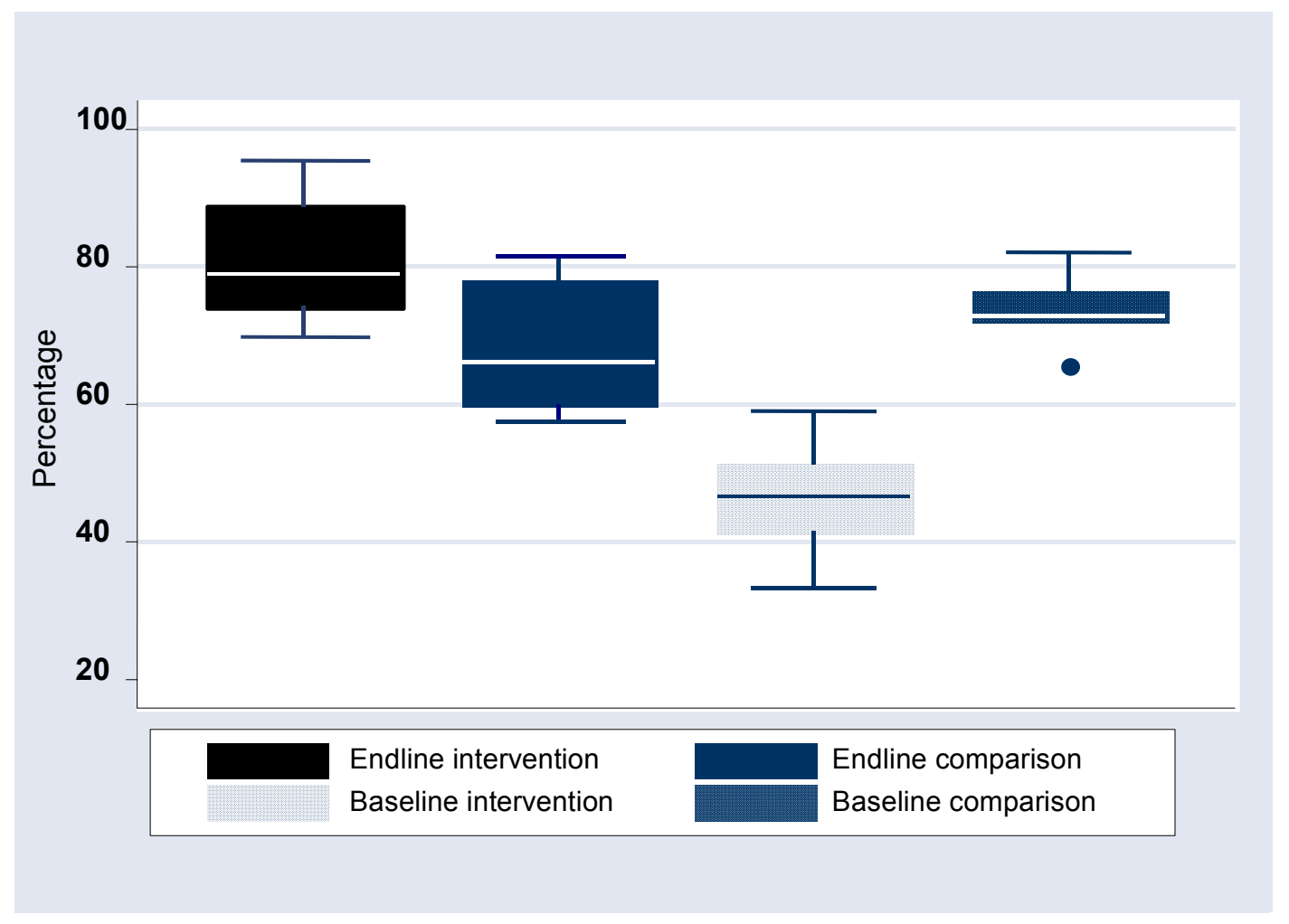

Figure 4 illustrates the proportion of providers who scored 70 percent and above by the endline for each of the six labour and delivery knowledge indicators. More providers in both groups reached the 70 percent score by the endline, with providers in the intervention group out-performing those in the comparison group $(\mathrm{p}<0.05)$. Performance was generally poor overall, however, with over half of providers in both groups failing to reach the 70 percent cut-off score; knowledge about taking medical/obstetric history and monitoring third stage of labour were the only indicators where more than half of the providers could be judged as competent. 
Figure 4: Providers scoring $70 \%$ and above in labour and delivery knowledge at endline

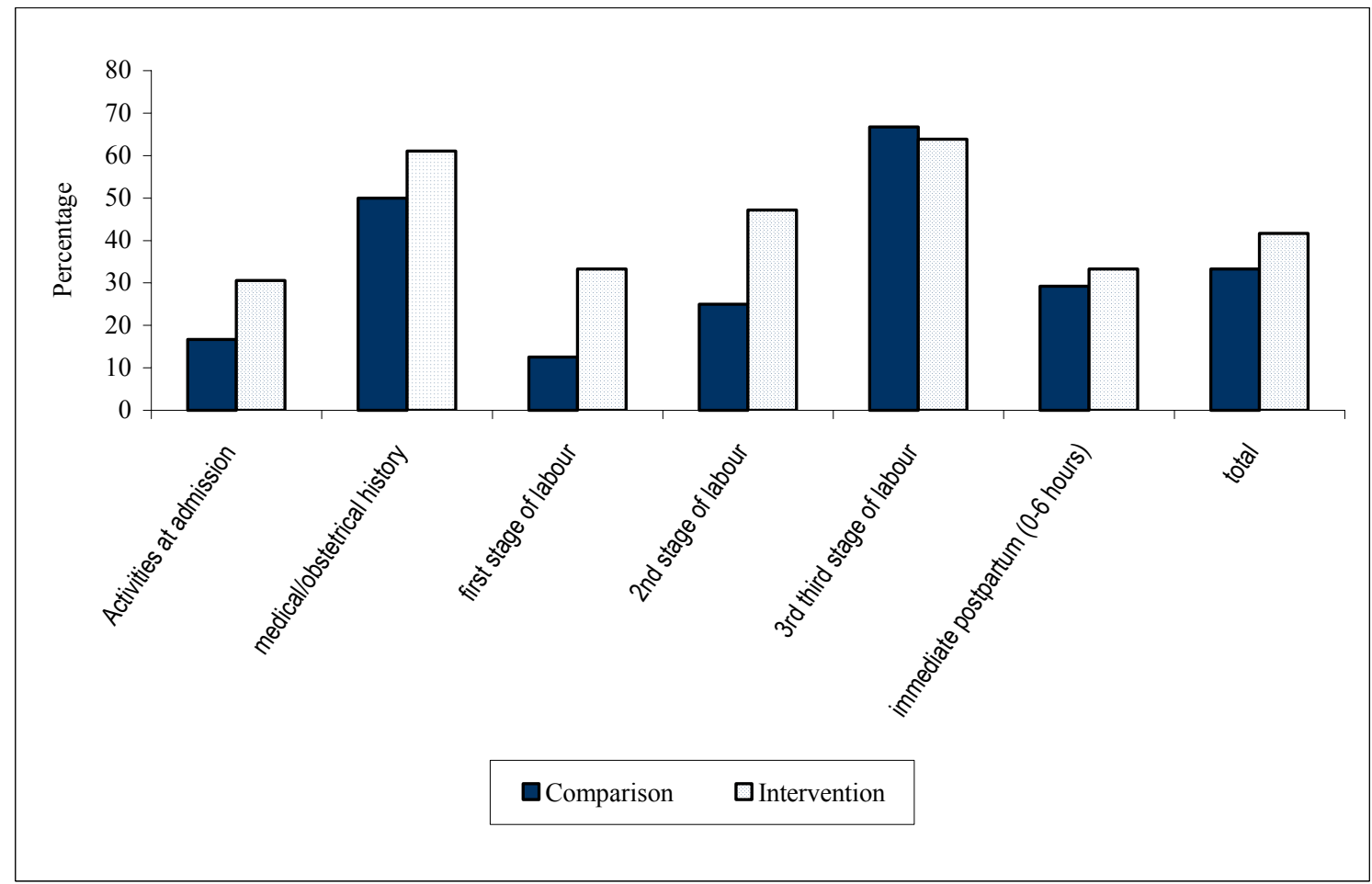

\section{Other organizational support}

Some shortcomings in the supervision of providers were found at baseline. By the endline, more providers in both groups stated that their safe motherhood activities were supervised (up from 80 percent to 89 percent in the intervention group and from 65 percent to 92 percent in the comparison group); however, neither of these improvements was statistically significant. Supervision was conducted mostly by the in-charges at the hospitals and by the District Health Management Teams (DHMTs) at the health centres. By the endline, RRT members had paid more supervisory visits to providers in the intervention group $(67 \%)$ than in the comparison group (29\%). The frequency of supervisory visits varied from zero to four times in the last six months in both groups and at both baseline and endline, with supervisors generally providing technical support and encouraging promotion of safe motherhood activities. Approximately one-third of providers stated at both the baseline and endline that they do not participate in decision-making.

Three-quarters of providers reported constraints in their safe motherhood work (at baseline and endline), mostly due to lack of equipment, supplies and inadequate staffing levels. At baseline, providers generally perceived their work as unsatisfactory. They were not satisfied with opportunities for learning and developing on the job (73\%), the amount of workload and number of hours $(68 \%)$ and the salary 88 percent. At endline, providers in both groups remained dissatisfied with their salary, equipment and supplies (Table 12). 
Table 10: Providers' perceptions about work at endline

\begin{tabular}{|l|c|c|}
\hline Proportion of staff expressing satisfaction with: & $\begin{array}{c}\text { Intervention } \\
\mathrm{n}=36 \\
\%\end{array}$ & $\begin{array}{c}\text { Comparison } \\
\mathrm{n}=24 \\
\%\end{array}$ \\
\hline Providing SM services & 92 & 96 \\
\hline Performance as a SM provider & 94 & 96 \\
\hline Work conditions & 72 & 71 \\
\hline Salary & 8 & 17 \\
\hline Equipment for SM work & 30 & 4 \\
\hline Commodities and supplies for SM & 33 & 13 \\
\hline Amount of SM work (workload, number of hours) & 44 & 63 \\
\hline Opportunities for learning and developing & 86 & 54 \\
\hline Expectation as a SM service provider & 97 & 83 \\
\hline Support from supervisors & 89 & 63 \\
\hline
\end{tabular}

\section{Quality of Care}

Quality was measured in terms of: contact with and experience of the clinic service; understanding what happens and why; respect and dignity received; and emotional support ${ }^{3}$. These indicators were measured through a combination of observations of client-provider interactions, client exit interviews, provider interviews and assessment of provider skills using simulated cases.

\section{Observation of client-provider interactions}

Overall, client-provider interactions were satisfactory at both baseline and endline for both intervention and control groups. The observers considered, among other things, how the provider greeted the client, whether there were any interruptions during the interaction, availability of privacy and whether the clients were allowed to ask questions. At baseline, providers were more likely to provide undivided attention in the intervention group $(62 \%)$ than in the comparison group (49\%). Auditory and visual privacy were generally satisfactory, although other people walked in and out of the room disrupting consultation in both intervention (36\%) and comparison (24\%) groups. Additionally, about a quarter of providers in both groups did not ask clients about their concerns with the pregnancy.

\section{Clients' perceptions of the interaction}

The majority of clients in both intervention and comparison groups felt that the provider treated them with respect; received all the information they needed, and did not feel uncomfortable during the consultation at baseline and endline. Some clients at baseline felt they were not given enough opportunity to ask questions (30 percent in the intervention group and 15 percent in the comparison group), but by endline, only 7 percent in both groups expressed this. About 30 percent of clients in both groups at endline felt that the waiting time was unreasonable, compared with about 20 percent at baseline.

3 These indicators were drawn from: Hulton, L., Z. Matthews and R. W. Stones. 2000. A Framework for the Evaluation of Quality of Care in Maternity Services, University of Southampton, UK. 


\section{Providers' performance}

Provider skills were measured as follows. Observations were undertaken of routine ANC client-provider interactions, and at baseline only, of women in labour and delivering. Because of the insufficient numbers of women presenting for delivery and PAC at baseline, simulated situations were used to assess provider skill in routine labour, delivery and PAC at endline. Due to their rarity, provider skills in managing obstetric complications and emergencies during antenatal care and in labour and delivery could not be observed, and so these were measured by assessing each provider's response to a series of standardized descriptions of obstetric emergency situations.

\section{Routine Antenatal Care}

As can be seen in Table 11, there was a wide range of scores across indicators for provider performance in providing routine antenatal care. Both groups performed slightly better at the endline, although these differences were not statistically significant. Particularly weak areas for routine ANC included laboratory investigation and client education; the stronger areas included abdominal examination and observing safety measures for blood sample taking.

Table 11: Provider performance in routine ANC

\begin{tabular}{|l|c|c|c|c|}
\hline \multirow{2}{*}{ Activity } & \multicolumn{2}{|c|}{ Intervention } & \multicolumn{2}{c|}{ Comparison } \\
\cline { 2 - 5 } & $\begin{array}{c}\text { Baseline } \\
\mathrm{n}=270 \\
\%\end{array}$ & $\begin{array}{c}\text { Endline } \\
\mathrm{n}=228 \\
\%\end{array}$ & $\begin{array}{c}\text { Baseline } \\
\mathrm{n}=228 \\
\%\end{array}$ & $\begin{array}{c}\text { Endline } \\
\mathrm{n}=135 \\
\%\end{array}$ \\
\hline Medical and behavioural history & 45 & 42 & 48 & 40 \\
\hline General physical exam & 46 & 58 & 49 & 62 \\
\hline Abdominal exam & 79 & 89 & 72 & 89 \\
\hline Vaginal exam & 67 & 50 & 33 & -- \\
\hline Take samples or refer for laboratory test & 12 & 23 & 20 & 18 \\
\hline Safety measures & 73 & -- & 79 & 93 \\
\hline Routine medications & 56 & 55 & 63 & 62 \\
\hline Issue/education & 23 & 42 & 38 & 42 \\
\hline Interaction & 52 & 83 & 56 & 83 \\
\hline Total & $\mathbf{5 0}$ & $\mathbf{5 5}$ & $\mathbf{5 1}$ & $\mathbf{6 1}$ \\
\hline
\end{tabular}

-- = No observations made

\section{Management of obstetric and other complications of pregnancy}

Providers in both groups showed some improvement in the mean scores in managing obstetric complications; however, these improvements were statistically significant only in the intervention group. As can be seen in Table 12, the mean score was particularly weak in postabortion care and neonatal care, especially for the intervention group; managing haemorrhages, however, scored relatively highly in both groups. 
Table 12: Group mean score of provider performance in managing obstetric and other complications of pregnancy

\begin{tabular}{|l|c|c|c|c|}
\hline \multirow{2}{*}{ Indicator } & \multicolumn{2}{c|}{ Intervention } & \multicolumn{2}{c|}{ Comparison } \\
\cline { 2 - 5 } & $\begin{array}{c}\text { Baseline } \\
\mathrm{n}=40 \\
\%\end{array}$ & $\begin{array}{c}\text { Endline } \\
\mathrm{n}=36 \\
\%\end{array}$ & $\begin{array}{c}\text { Baseline } \\
\mathrm{n}=37 \\
\%\end{array}$ & $\begin{array}{c}\text { Endline } \\
\mathrm{n}=24 \\
\%\end{array}$ \\
\hline Labour and delivery abnormalities & 56 & 58 & 57 & 54 \\
\hline Haemorrhages & 58 & 66 & 65 & 72 \\
\hline Concurrent diseases & 47 & 56 & 54 & 52 \\
\hline Other diseases & 45 & 54 & 54 & 64 \\
\hline Neonatal care & 48 & 48 & 50 & 54 \\
\hline Postabortion care & 37 & 46 & 43 & 52 \\
\hline Total & $\mathbf{4 9}$ & $\mathbf{5 5 * *}$ & $\mathbf{5 4}$ & $\mathbf{5 8}$ \\
\hline
\end{tabular}

$* * p<0.05$

Evidence of better performance in managing obstetric complications at endline by the comparison group than by the intervention group can be seen in Figure 5. Although the intervention group has a slightly higher median score (55\% vs. 54\%), most of the scores fall below the median while in the comparison group most are above the median; the difference between the two groups at endline is not statistically significant. However, the SPL intervention significantly improved performance over time $(p=0.014)$ and thus this intervention appears to be more effective than the traditional approach in improving these skills.

Figure 5: Providers' performance and skills in managing complications

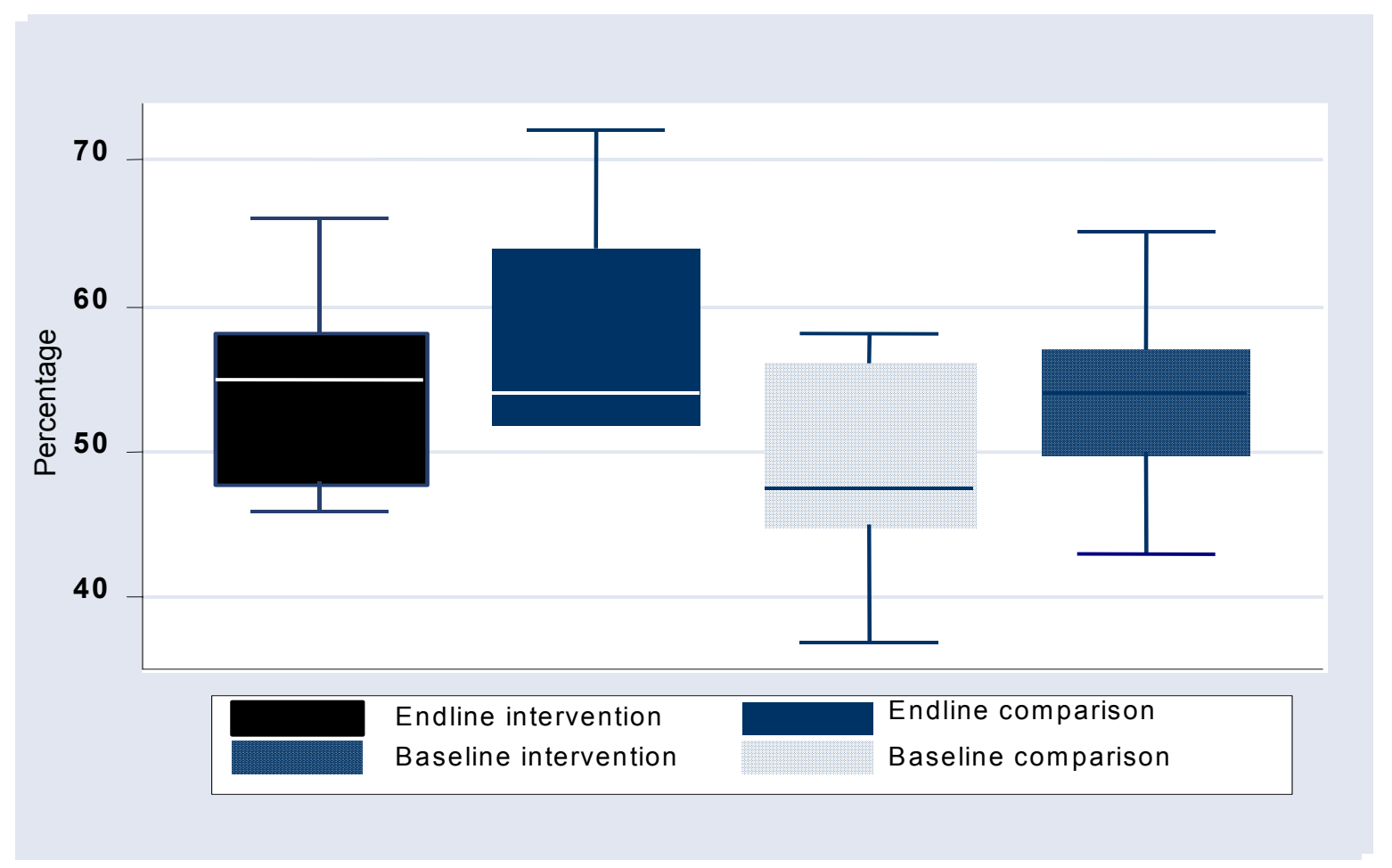




\section{Labour and Delivery}

At endline, the simulated cases covered manual removal of placenta, internal bimanual compression, episiotomy and management of third stage of labour. In addition, providers interpreted and analysed completed partographs. As indicated in Figure 6, both groups performed well in labour and delivery skills, with an average score across the four skills of 70 percent in the intervention group and 74 percent in the comparison group. This difference was statistically significant $(\mathrm{p}<0.05)$.

Figure 6: Provider's skill performance in labour and delivery

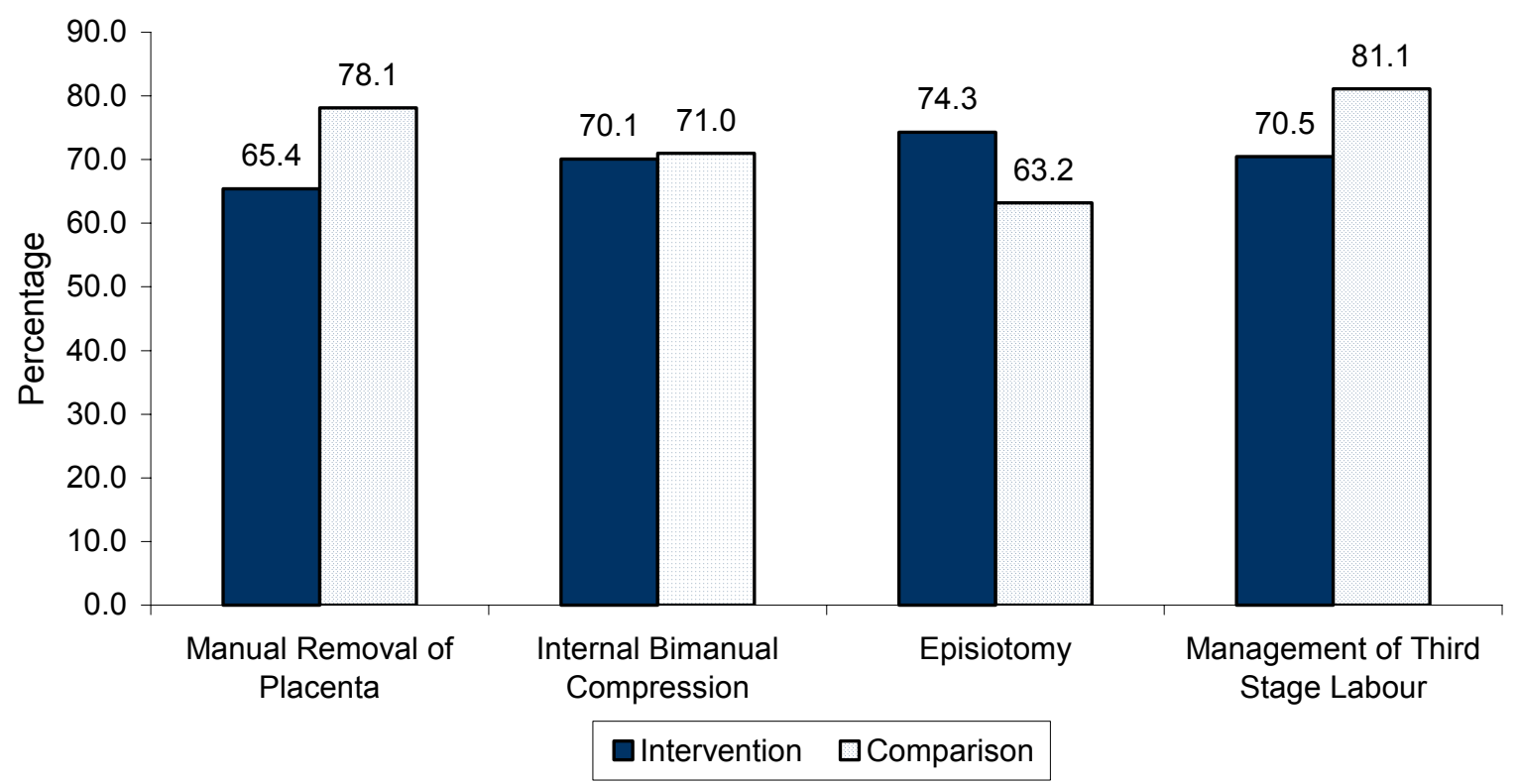

Performance in interpreting the partographs in both groups was poor. Apart from monitoring the active phase and assessing transfer of readings on the partograph, providers in both intervention and comparison groups scored, on average, below 50 percent for all other areas assessed, i.e. determining the period from admission to delivery, completing or filling of partograph, making a diagnosis and assessing management (see Figure 7). 
Figure 7: Provider's performance in use of the partograph

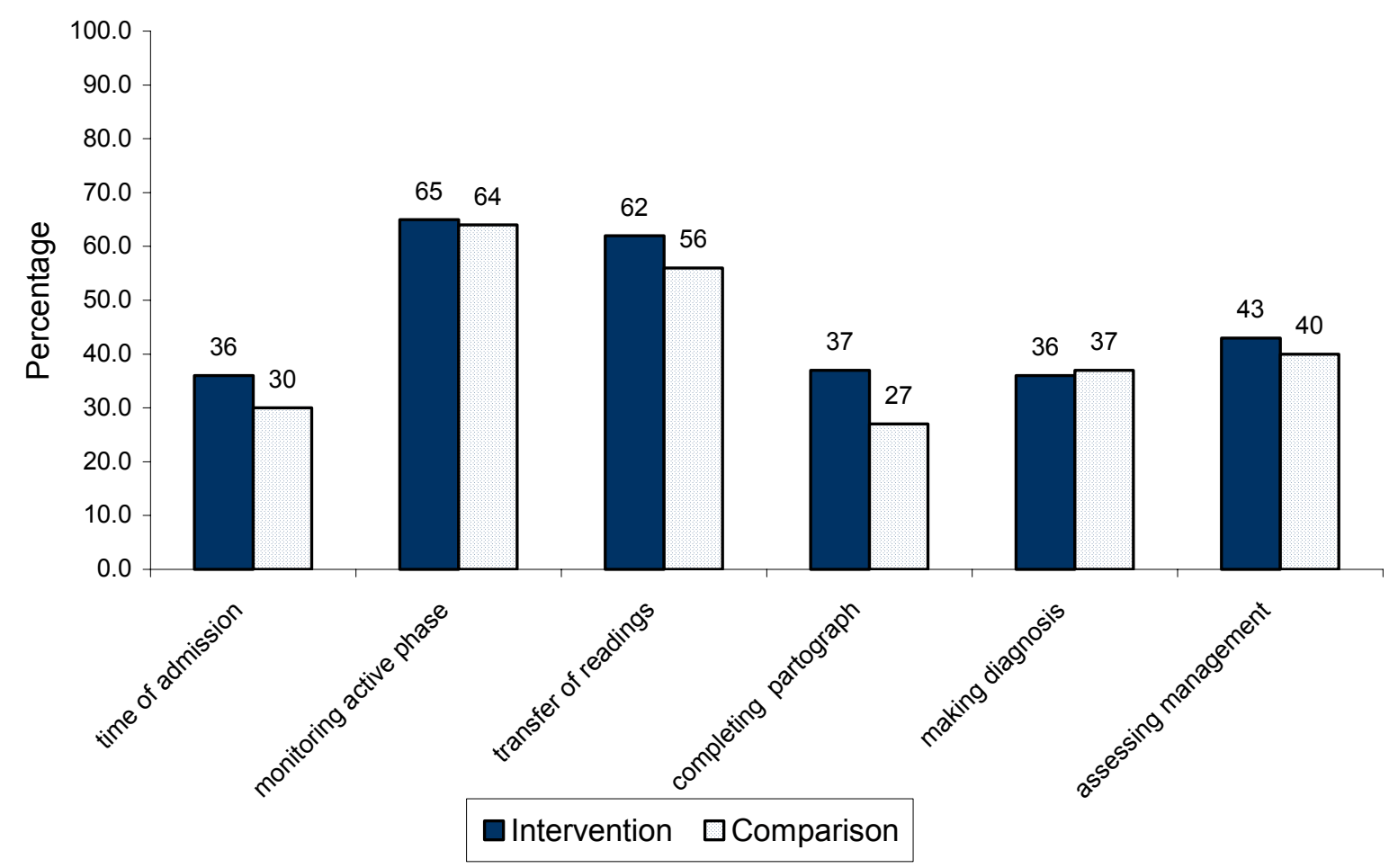

Figure 8 shows the distribution of the mean scores for the six indicators measured in the partograph analysis and indicates that the performance of the intervention group was significantly better than the comparison group $(\mathrm{t}=2.57, \mathrm{p}=0.05)$.

Figure 8: Group comparison of provider performance in partograph analysis

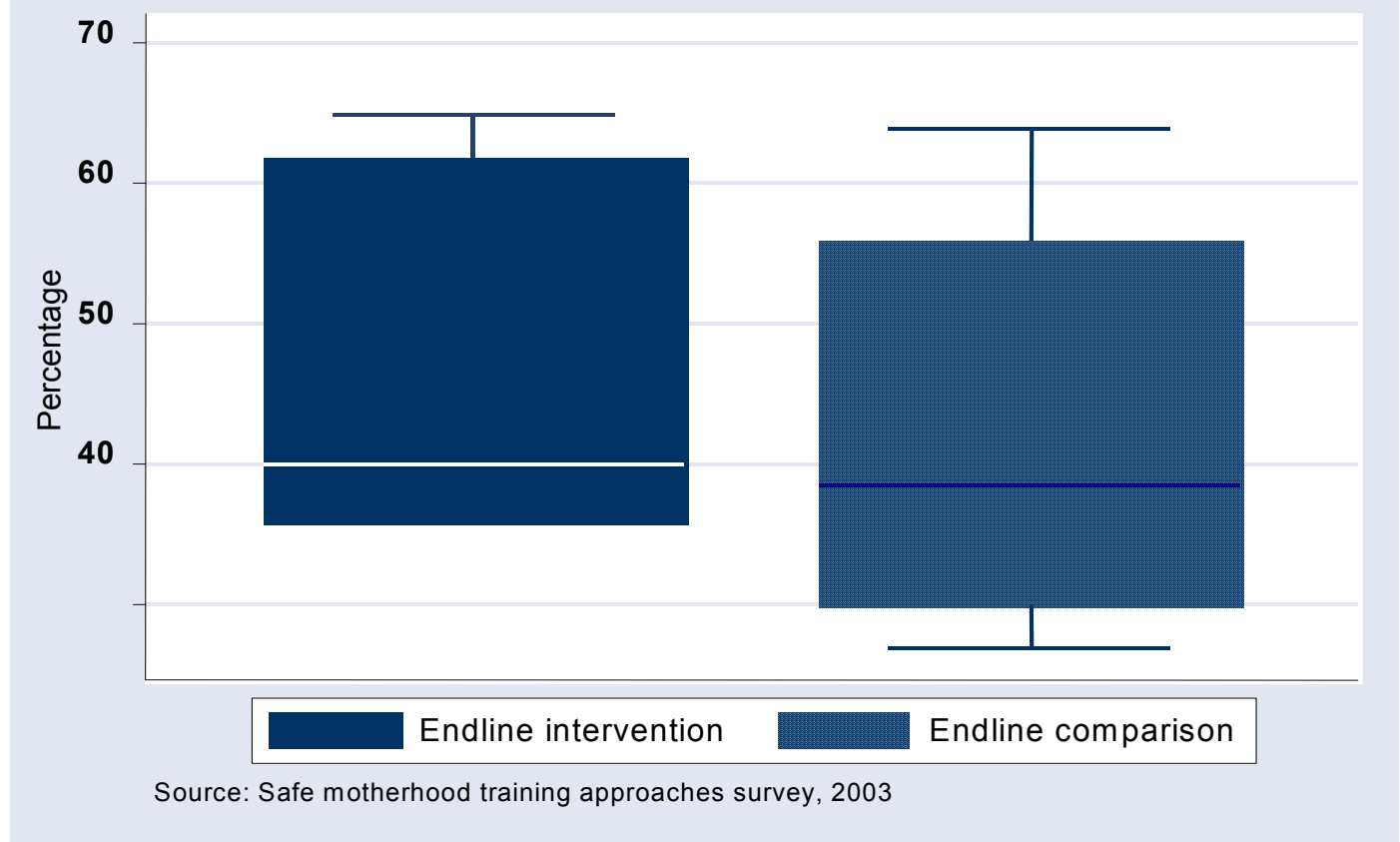




\section{Postabortion Care}

Provider competence in managing postabortion care at endline was assessed by observing simulated cases of manual vacuum aspiration and postabortion family planning counselling skills. Thirteen providers (seven in the intervention and six in the comparison group) had not undergone training in the manual vacuum aspiration module because they were not midwives, and for some the practical session was delayed, and so these have not been included in the assessment. Figure 9 shows the mean scores achieved. The differences were not statistically significant.

\section{Figure 9: Provider Skills in Post Abortion Care at endline}

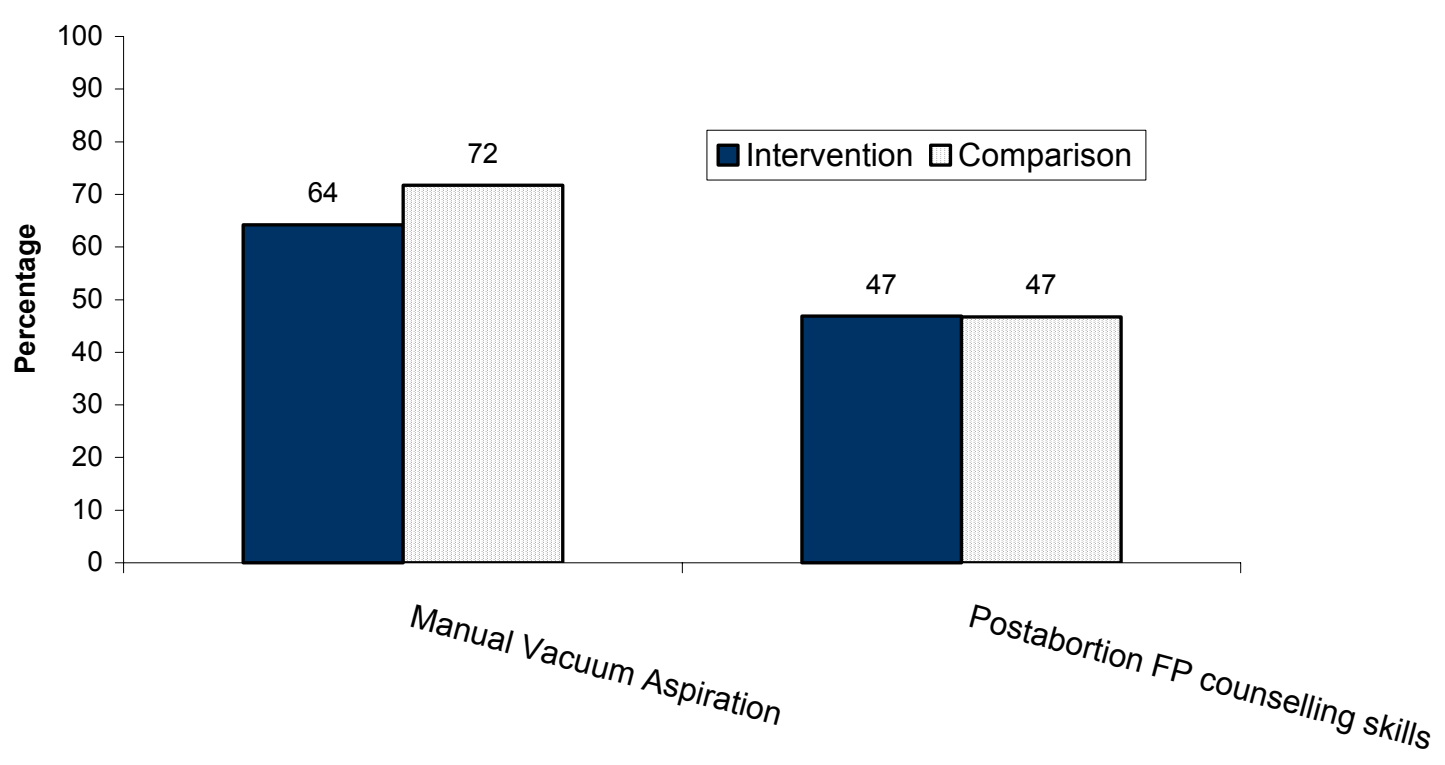

\section{Client Health Outcomes}

Improving the quality of safe motherhood services is intended to enhance the likelihood of a safe delivery and better health outcomes for the mother and child. Data were collected from the study clinics on selected indicators (antenatal care, labour and delivery, postabortion care, postnatal care, family planning and complications of pregnancy) by analysing client records for the 12 months prior to the baseline and endline surveys.

\section{Quality and completeness of service statistics data}

All facilities visited had complete 12-month service statistics for those indicators that are routinely reported on the monthly reproductive and child health reporting formats ${ }^{4}$. Some indicators, such as weight, height, blood pressure, laboratory test, discussion on health issues, and drugs given are recorded on individual client cards and so the records for these indicators in the hospital attendance books could not be verified.

\section{Volume of services recorded during the last calendar year}

As would be expected, the volume of services provided varies according to the facility level, with hospitals generally seeing more patients than health centres (see Appendix 2), except for services for the pill and condom in the intervention districts. The volume of services was similar in both intervention and comparison group site; the differences observed in Table 13 are not statistically significant.

$4 \quad$ One hospital in the comparison group did not have complete data for condoms, IUDs, foaming tablets and Norplant. 
Table 13: Average number of clients per facility

\begin{tabular}{|c|c|c|c|c|}
\hline \multirow[t]{2}{*}{ Indicator } & \multicolumn{2}{|c|}{ Intervention } & \multicolumn{2}{|c|}{ Comparison } \\
\hline & $\begin{array}{c}\text { Baseline } \\
(n=21)\end{array}$ & $\begin{array}{l}\text { Endline } \\
(\mathrm{n}=21)\end{array}$ & $\begin{array}{c}\text { Baseline } \\
(n=17)\end{array}$ & $\begin{array}{l}\text { Endline } \\
(\mathrm{n}=17)\end{array}$ \\
\hline Antenatal registrants & 403 & 424 & 493 & 364 \\
\hline Total ANC visits & 1120 & 766 & 1266 & 840 \\
\hline No. of pregnant women receiving tetanol & 463 & 698 & 577 & 207 \\
\hline Normal vaginal delivery & 90 & 117 & 106 & 110 \\
\hline Complicated vaginal delivery & 2 & 2 & 4 & 4 \\
\hline Caesarean section & 7 & 7 & 7 & 8 \\
\hline Induced abortions performed & 0 & 5 & 5 & 2 \\
\hline Postabortion care clients & 1 & 16 & 8 & 0 \\
\hline $\begin{array}{l}\text { Postabortion care clients accepting family } \\
\text { planning immediately }\end{array}$ & 0 & 6 & 2 & 0 \\
\hline Postnatal registrants & 166 & 201 & 160 & 134 \\
\hline Babies first 6 week vaccination & 334 & 277 & 242 & 193 \\
\hline New and continuing users of FP & 500 & 450 & 419 & 450 \\
\hline Pills & 72 & 99 & 43 & 40 \\
\hline Condoms (male and female) & 117 & 485 & 34 & 40 \\
\hline IUD & 11 & 5 & 4 & 0 \\
\hline Foaming tablets & 23 & 39 & 3 & 1 \\
\hline Injectables & 322 & 433 & 366 & 336 \\
\hline Norplant & 25 & 18 & 20 & 2 \\
\hline Vasectomy & 0 & 0 & 0 & 0 \\
\hline Tubal Ligation & 0 & 2 & 0 & 0 \\
\hline Eclampsia & 1 & 1 & 0 & 0 \\
\hline Severe malaria & 11 & 22 & 12 & 2 \\
\hline Antepartum haemorrhage & 1 & 2 & 1 & 0 \\
\hline Dysfunctional labour (prolonged/obstructed) & 3 & 5 & 4 & 1 \\
\hline Uterine rupture & 2 & 1 & 2 & 0 \\
\hline Postpartum haemorrhage & 1 & 2 & 2 & 0 \\
\hline Postpartum infection (sepsis) & 1 & 1 & 1 & 0 \\
\hline Premature births & 1 & 3 & 1 & 1 \\
\hline Still Birth & 3 & 4 & 1 & 0 \\
\hline Neonatal deaths & 0 & 3 & 0 & 0 \\
\hline Ectopic pregnancy & 0 & 1 & 0 & 0 \\
\hline Retained placenta & 1 & 2 & 1 & 1 \\
\hline Incomplete abortion (Retained products) & 2 & 5 & 4 & 2 \\
\hline Maternal deaths & 0 & 1 & 0 & 0 \\
\hline
\end{tabular}




\section{COSTS OF LEARNING APPROACHES}

\section{Financial cost}

Table 14 shows the total and average financial costs for each of the learning approaches. Overall, the financial cost for the SPL approach is approximately $14 \%$ higher per person than the traditional residential approach.

Table 14: Financial cost of SPL and traditional training approaches

\begin{tabular}{|c|c|c|c|c|}
\hline \multirow{2}{*}{ Cost Category } & \multicolumn{2}{|c|}{ SPL } & \multicolumn{2}{|c|}{ Residential } \\
\hline & Cedis & Dollars & Cedis & Dollars \\
\hline \multicolumn{5}{|l|}{ Travel \& Transport } \\
\hline Learners & $26,216,500$ & 3,277 & $6,578,000$ & 822 \\
\hline RRT & $11,210,500$ & 1,401 & $3,320,000$ & 415 \\
\hline Clinical Instructors & 170,000 & 21 & 0 & 0 \\
\hline RHMT/DHMT/Other & $7,194,500$ & 899 & $3,663,000$ & 458 \\
\hline Subtotal & $44,791,500$ & 5,599 & $13,561,000$ & 1,695 \\
\hline Average & $1,119,788$ & 140 & 180,813 & 24 \\
\hline \multicolumn{5}{|l|}{ Per diem } \\
\hline Learners & $172,240,000$ & 21,530 & $263,600,000$ & 32,950 \\
\hline RRT & $73,640,000$ & 9,205 & $180,150,000$ & 22,519 \\
\hline Clinical Instructors & 545,000 & 68 & 0 & 0 \\
\hline RHMT/DHMT/Other & $11,293,600$ & 1,412 & $34,711,400$ & 4,339 \\
\hline Subtotal & $257,718,600$ & 32,215 & $478,461,400$ & 59,808 \\
\hline Average & $6,442,965$ & 805 & $6,379,485$ & 854 \\
\hline \multicolumn{5}{|l|}{ Resource Person Allowance } \\
\hline RRT & $21,300,000$ & 2,663 & $79,314,286$ & 9,914 \\
\hline Clinical Instructors & $10,200,000$ & 1,275 & $15,000,000$ & 1,875 \\
\hline RHMT/DHMT/Other & $44,037,600$ & 5,505 & $14,105,600$ & 1,763 \\
\hline Subtotal & $75,537,600$ & 9,442 & $108,419,886$ & 13,552 \\
\hline Average & $1,888,440$ & 236 & $1,445,598$ & 194 \\
\hline \multicolumn{5}{|l|}{ Other Direct Costs } \\
\hline Rentals & 700,000 & 88 & $7,295,238$ & 912 \\
\hline Gasoline & $2,879,030$ & 360 & $5,128,900$ & 641 \\
\hline Training supplies & $4,860,000$ & 608 & $17,832,500$ & 2,229 \\
\hline Communications & 0 & 0 & 607,500 & 76 \\
\hline Photocopies & $25,174,385$ & 3,147 & $3,149,500$ & 394 \\
\hline Other & 44,500 & 6 & 162,000 & 20 \\
\hline Subtotal & $33,657,915$ & 4,207 & $34,175,638$ & 4,272 \\
\hline Average & 841,448 & 105 & 455,675 & 61 \\
\hline TOTAL & $411,705,615$ & 51,463 & $634,617,923$ & 79,327 \\
\hline Average cost per Learner & $10,292,640$ & 1,287 & $8,461,572$ & 1,133 \\
\hline
\end{tabular}


As can be seen in Figures 10 and 11, the single largest financial cost for both learning approaches is per diem, and this is slightly higher for the residential approach. One of the reasons for this is that all of the activities for which per diems were paid for this group took place in the regional capital where higher per diem rates apply. For the SPL approach, only the one-week Foundations Unit took place in the regional capital, and lower per diem rates applied for other SPL activities.

The Resource Person Allowances is the second highest cost category for both approaches, but are distributed differently across the categories of resource persons, thus reflecting the differences in the way that resource persons are used for each approach. Travel \& Transport is the third highest cost category for the SPL approach because of the higher number of short duration trips needed for this approach. Other Direct Costs is the third highest category for the residential approach due to the cost of venue hire and supplies for the longer period of classroom-based training. For both approaches, per diems and resource person allowances would be the categories where greatest savings could potentially be realized.

Figure 10: Financial cost of SPL approach

\section{Figure 11: Financial cost of Traditional approach}

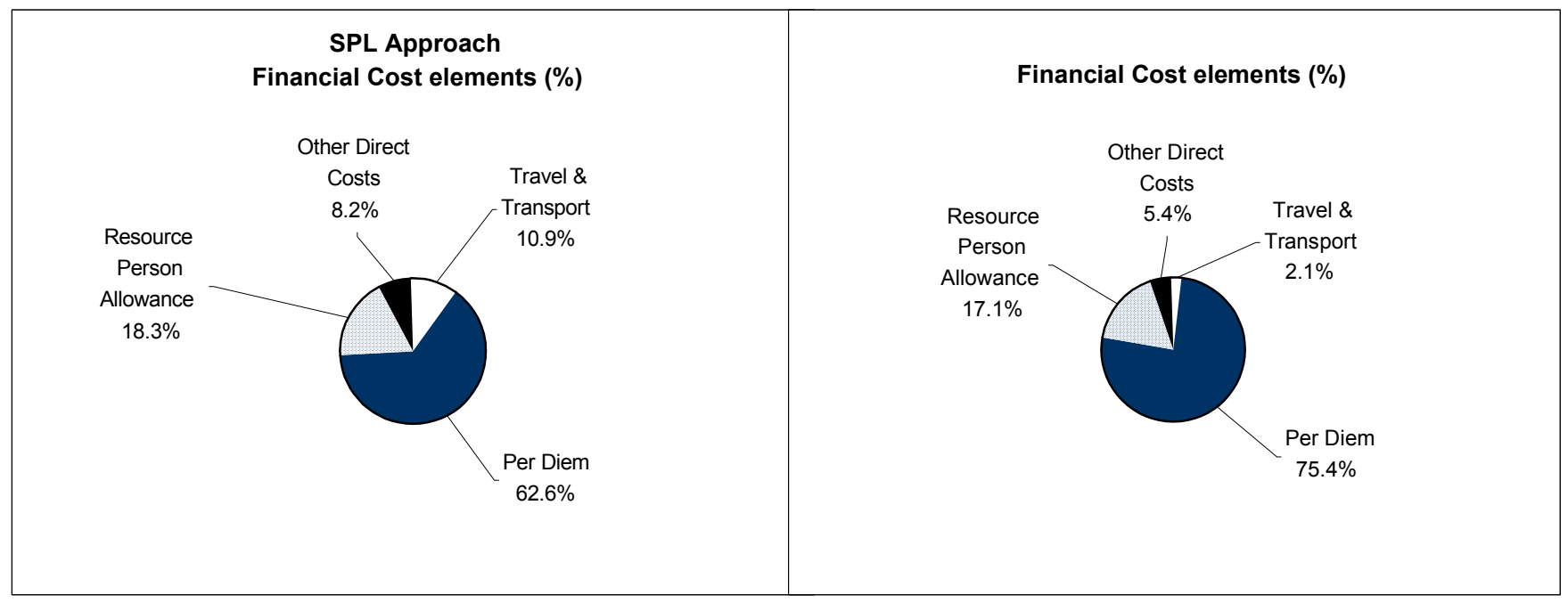

A variation of the SPL design that was identified during monitoring visits and expense tracking was that some learner pairs decided to combine some of the planned trips to RRTs, trips for Demonstration and trips for Clinical Practice. This had the effect of reducing the travel and per diem costs for the SPL approach compared to the amounts that would have been incurred if separate trips had been made for each of these activities. On the other hand, there were also reports of additional visits made by some learner pairs to each other to help them understand the content of units. Therefore, reduced spending for one type of visit may have been partially offset by higher spending on visits to peers.

\section{Opportunity costs}

Opportunity costs are calculated by multiplying the amount of time devoted to the SPL and Traditional approaches by the learners and other personnel involved by the unit cost of their time, including benefits. This conversion of the unit of time into a financial unit (i.e. cedis and dollars) provides a common denominator for purposes of comparison. It is important to 
keep in mind that the cost of personnel time is a "sunk cost" or already incurred cost to the $\mathrm{MOH}$, and so does not represent a new financial expenditure for either of the learning approaches. Therefore, although opportunity costs should be considered when evaluating the alternative approaches because they are a cost to the $\mathrm{MOH}$, because that time could have been spent providing services or undertaking some other job-related work, it is recommended that greater weight be given to the financial cost.

Table 15 shows the opportunity costs for each approach, both in terms of hours per category of personnel and the value of those hours when multiplied by the salary and fringe benefit rates of the personnel. These data show that the time required by SPL learners and other categories of personnel is over three times higher for the SPL approach than for the traditional residential approach.

Table 15: Average hours and value of time per personnel category by approach

\begin{tabular}{|l|c|c|c|c|c|c|}
\hline \multirow{2}{*}{ Personnel Category } & \multicolumn{3}{|c|}{ SPL } & \multicolumn{3}{c|}{ Traditional } \\
\cline { 2 - 7 } & Hours & Cedis & Dollars & Hours & Cedis & Dollars \\
\hline Learner & 511 & $5,561,585$ & 695 & 116 & $1,262,513$ & 158 \\
\hline RRT & 72 & 707,667 & 88 & 16 & 160,392 & 20 \\
\hline Clinical Instructor & 44 & 347,393 & 43 & 11 & 88,437 & 11 \\
\hline RHMT / DHMT & 27 & 316,654 & 40 & 5 & 64,459 & 8 \\
\hline Total & $\mathbf{6 5 4}$ & $\mathbf{6 , 9 3 3 , 2 9 9}$ & $\mathbf{8 6 7}$ & $\mathbf{1 4 8}$ & $\mathbf{1 , 5 7 5 , 8 0 1}$ & $\mathbf{1 9 7}$ \\
\hline
\end{tabular}

It is important, however, to consider other factors besides simply the number of hours when examining opportunity costs. These costs are classified as opportunity costs because the salaries of the learners, RRT members, Clinical Instructors, among others are already paid by the Ghana Health Service and so are not a financial cost requiring an additional expenditure. Although the average hours per SPL learner is higher than per Traditional learner, factors such as when and where the hours were used and the related impacts on service delivery need to be considered. For example, most of the time spent by the SPL learners on "theory" (about 40 percent of the total SPL learner time) is time that is either outside of the provider's regular clinic hours (e.g., nights or weekends) or is time that the provider is not otherwise busy seeing patients. Thus, the use of this time has minimal negative impact on the provider's availability for service delivery, although it clearly requires that the provider be willing to contribute their personal rather than work time for the training. If these hours occur outside the formal working time, it could be argued that it is not necessary to convert them into financial costs for the GHS, although this has been done to illustrate the total overall cost of this approach.

As noted above, it was anticipated that there would be wide variations in the time required by SPL learners to complete the various units, and this indeed proved to be the case. In contrast, it was assumed that the time required for the Traditional approach would be the same for all learners due to the more structured nature of the training. For this reason, actual learner time was not measured for the Traditional approach but was estimated based on the time spent on formal training. It is possible that the Traditional learners may have used the curricula they received for self-study and review after the formal training was completed, but such activity was not measured. 
In comparing opportunity costs for each approach, the overall duration for completing the curriculum, as well as the total number of hours required, should be considered. For each batch of Traditional learners, the duration of their training was three weeks, whereas for the SPL learners the time was spread out over 4-6 months.

As would be expected, the time spent by the learners on the training activities accounted for about $78 \%$ of the personnel hours devoted to both the SPL and Traditional approaches. These figures indicate that learner time is clearly the personnel category with the highest opportunity cost for both approaches.

Figure 12 shows the breakdown of SPL learner time by category of activities, which along with the cost data, could help inform adjustments that could be made to the SPL approach if it is considered for replication.

Figure 12: Percentage of learner time by category of activities (SPL)

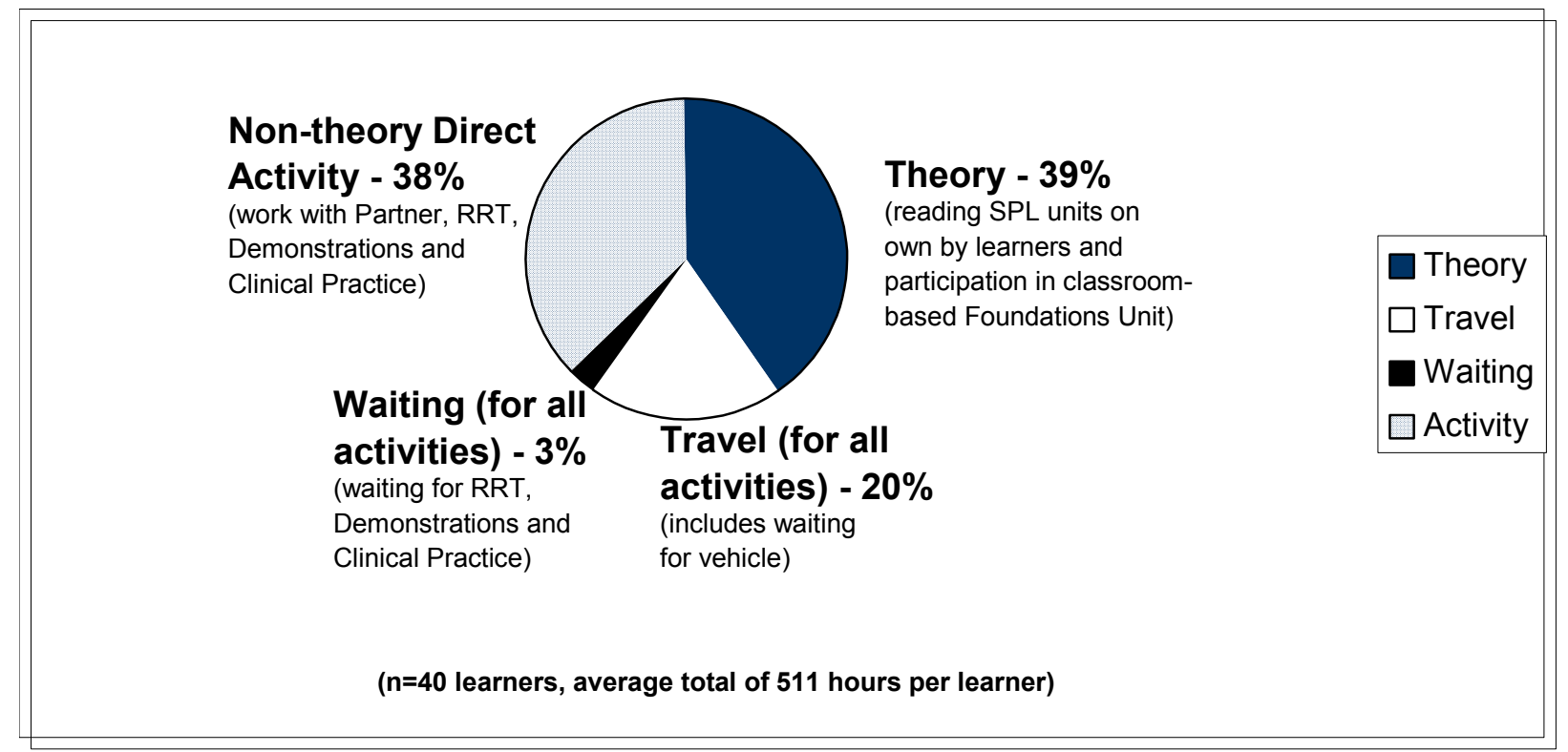

\section{Combined Financial and Opportunity costs}

Figure 13 compares the combined financial and opportunity costs for each approach. Financial cost accounts for most of the cost of both approaches and the primary difference between the two approaches is in opportunity cost. This observation is noteworthy in terms of the importance that decision-makers may assign to each of the types of cost and to the linkage between costs and results, which can be expressed as cost-effectiveness analysis. 
Figure 13: Combined financial and opportunity costs per learner

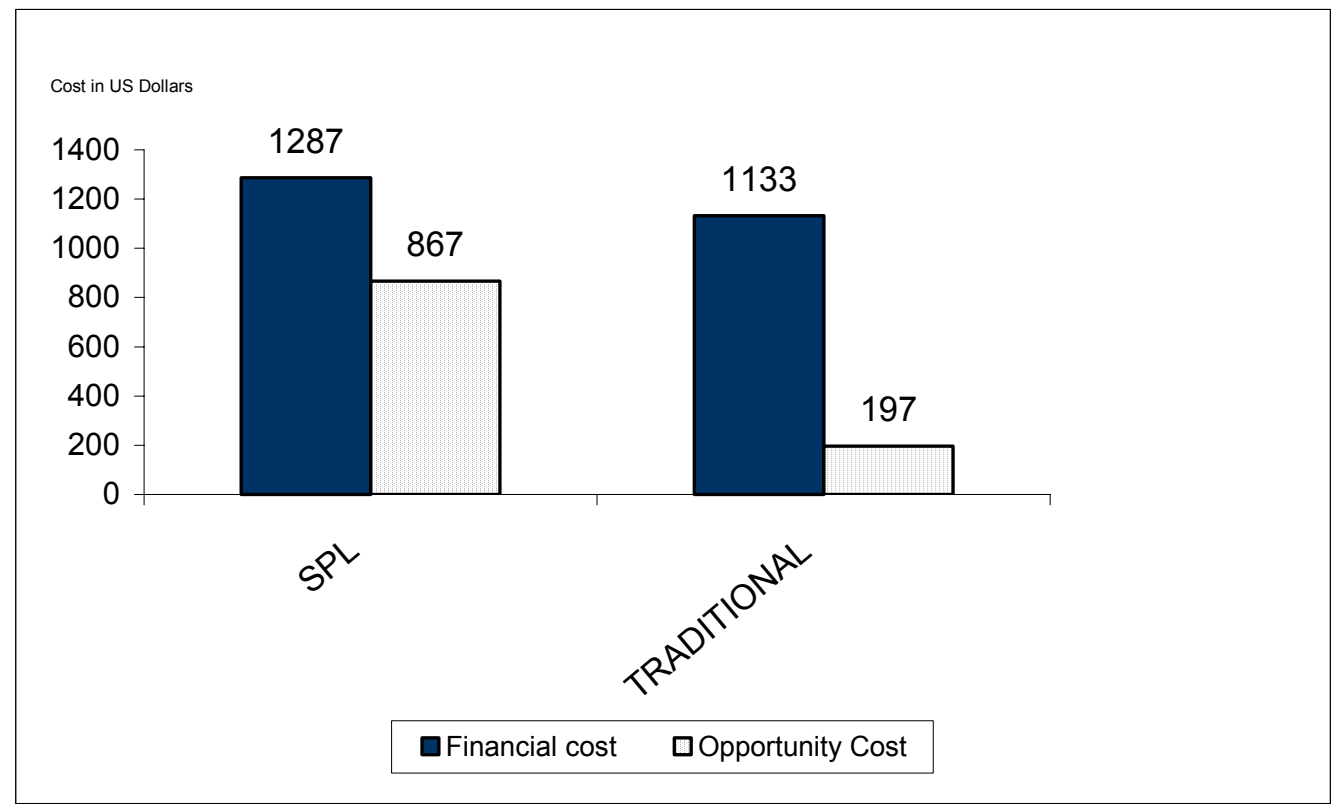

\section{Cost-effectiveness of the SPL and Traditional approaches}

Cost-effectiveness is defined as the ratio of the unit cost per learner for a selected indicator. Two groups of summary effectiveness indicators were identified for this comparison of learning approaches, and the scores have been presented above: provider knowledge (see Tables 8 and 9) and provider performance (see Tables 11 and 12). In this section, these indicators are linked first with financial cost, and then with financial and opportunity costs combined (as presented above), to compare the cost-effectiveness of the two approaches.

Table 16 summarises changes over time in the effectiveness indicators in terms of the magnitude of change, both in percentage points and as a proportion of the baseline measure. It also gives the average financial cost, and the average financial plus opportunity cost, per provider per percentage change in an indicator. 
Table 16: Cost-effectiveness analysis of the SPL and Traditional Residential learning approaches

\begin{tabular}{|c|c|c|c|c|c|c|c|c|c|c|c|c|c|}
\hline \multirow{3}{*}{ 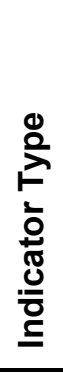 } & \multirow[t]{3}{*}{ Indicator Description } & \multicolumn{4}{|c|}{ Change in Indicator } & \multicolumn{2}{|c|}{$\begin{array}{l}\text { Change in } \% \\
\text { points }\end{array}$} & \multicolumn{2}{|c|}{$\begin{array}{l}\text { Proportional } \\
\text { change }\end{array}$} & \multicolumn{2}{|c|}{$\begin{array}{c}\text { Average } \\
\text { financial cost } \\
\text { (\$) per } \\
\text { provider per } \\
\% \text { change }\end{array}$} & \multicolumn{2}{|c|}{$\begin{array}{c}\text { Average } \\
\text { financial and } \\
\text { opportunity } \\
\text { cost }(\$) \text { per } \\
\text { provider per } \\
\% \text { change } \\
\end{array}$} \\
\hline & & \multicolumn{2}{|c|}{ SPL } & \multicolumn{2}{|c|}{ Traditional } & \multirow[b]{2}{*}{ SPL } & \multirow[b]{2}{*}{ Trad. } & \multirow[b]{2}{*}{ SPL } & \multirow[b]{2}{*}{ Trad. } & \multirow[b]{2}{*}{ SPL } & \multirow[b]{2}{*}{ Trad. } & \multirow[b]{2}{*}{ SPL } & \multirow[b]{2}{*}{ Trad. } \\
\hline & & Baseline & Endline & Baseline & Endline & & & & & & & & \\
\hline \multirow[b]{2}{*}{ 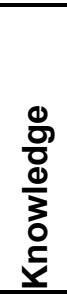 } & $\begin{array}{l}\text { Group mean score of } \\
\text { provider knowledge } \\
\text { on ANC }\end{array}$ & 54 & $67^{* * *}$ & 61 & 59 & 13 & -2 & $24 \%$ & $-4 \%$ & 69 & -- & 116 & -- \\
\hline & $\begin{array}{l}\text { Group mean score of } \\
\text { provider knowledge } \\
\text { on Labour and } \\
\text { Delivery }\end{array}$ & 43 & $61^{* * *}$ & 57 & 54 & 17 & -3 & $40 \%$ & $-5 \%$ & 28 & -- & 47 & -- \\
\hline \multirow{3}{*}{ 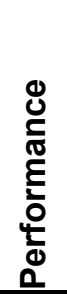 } & $\begin{array}{l}\text { Routine ANC } \\
\text { (combined measures) }\end{array}$ & 50 & 55 & 51 & 61 & 5 & 10 & $10 \%$ & $21 \%$ & 25 & 25 & 43 & 30 \\
\hline & $\begin{array}{l}\text { Managing obstetric } \\
\text { and other } \\
\text { complications }\end{array}$ & 49 & $55^{* *}$ & 54 & 58 & 6 & 4 & $13 \%$ & $8 \%$ & 101 & 138 & 168 & 162 \\
\hline & Postabortion Care & 37 & 46 & 43 & 52 & 10 & 9 & $26 \%$ & $22 \%$ & 50 & 53 & 83 & 62 \\
\hline
\end{tabular}

-- This value is not calculated due to the negative change in the indicator from baseline to endline 
The SPL approach led to significant improvements on both provider knowledge indicators, whereas the traditional residential approach had no significant effect on either indicator of provider knowledge. In terms of provider performance, the SPL approach significantly improved performance in managing obstetric and other complications, and improved performance in routine ANC or PAC, but the increase was not statistically significant. The traditional approach also improved provider performance in all three services, but none of the increases were statistically significant. On the evidence of the effectiveness indicators, therefore, it can be concluded that the SPL approach is more effective than the traditional approach in improving provider knowledge, and is slightly more effective at improving performance in managing obstetric and other complications. There is no difference between the approaches in terms of improving routine ANC and PAC performance.

In terms of both financial and financial plus opportunity costs, the traditional residential approach was less costly per provider trained than the SPL approach. In such situations, where one approach is more effective and the other less costly, a cost-effectiveness analysis is crucial in decision-making on which approach to scale up.

For provider knowledge, the SPL approach was clearly more cost-effective because the traditional residential approach was not at all effective, and so a cost-effectiveness ratio could not be calculated. When financial costs only are considered for provider performance, there was virtually no difference between the two approaches for routine ANC or PAC performance, but for EOC performance the SPL approach was more cost-effective. When financial and opportunity costs are combined, however, the traditional residential approach was more cost-effective than the SPL approach for all three performance indicators.

In summary, when the overall costs of including the time spent by providers attending the training approaches is considered along with the financial cost to the GHS of implementing them, the SPL approach is more cost-effective for improving providers knowledge and skills, whereas the traditional residential approach is more cost-effective for improving provider performance in ANC, EOC and PAC. 


\section{Conclusions and Recommendations}

This study set out to compare the effectiveness, cost and cost-effectiveness of a relatively new approach to training providers in safe motherhood services, known as the SPL approach, with the 'traditional' three-week residential approach currently used by the GHS. Overall, the findings indicate that several performance improvement factors that were also addressed (e.g. provision of equipment and supplies, reinforcement of organizational support and the development of job descriptions and feedback mechanisms) remained inadequate even after attempts to strengthen them, although the clinic environment for each level was found to be sufficient to offer the minimal and normal safe motherhood services as outlined in the National Reproductive Health Policy and Standards. Supplies of equipment and medications met acceptable levels for safe motherhood service delivery, especially at the hospitals.

Inadequacies remaining after interventions included: scarce storage facilities for vaccines; rooms designated for services are not spacious or do not allow privacy; health centres generally remained poorly equipped, with many missing basic items (including urine-testing kits, partographs, catheters, vacuum extractors and oxygen for resuscitation), although all facilities were well stocked with safe motherhood medications. Transport for referral was virtually non-existent in all health centres although a few had acquired vehicles by the endline. Feedback and supervision remained unsystematic and infrequent, and performance feedback and staff motivation remain problematic.

Before the training, the mean summary scores for a range of knowledge indicators were below the 70 percent cut-off score for the majority of providers. After the training, only providers in the SPL group exhibited improvements in their group mean summary scores, with statistically significant improvements of 24 and 46 percent achieved.

In relation to indicators of provider performance, both approaches registered improvements across all three areas evaluated (routine ANC, managing obstetric and other complications, and PAC) of between $10-26$ percent for the SPL approach and $8-22$ percent for the traditional residential approach. The only increase that was statistically significant, however, was for skills in managing obstetric and other complications among the SPL group. Both groups performed well in labour and delivery skills; however, there was a statistically significant difference in the average score across the four skills of 70 percent in the intervention group and 74 percent in the comparison group.

The SPL approach costs more per trainer than the traditional residential approach, both in financial costs and when opportunity costs are added to financial costs. As it also proved more effective in improving knowledge and in skills for managing obstetric and other complications, however, a cost-effectiveness analysis was undertaken to provide a balanced comparison. For improving provider knowledge, the SPL approach was clearly more costeffective because the traditional residential approach was not at all effective. When financial costs only were considered, there was no difference between the two approaches for improving routine ANC or PAC performance, but for performance in managing obstetric and other complications the SPL approach was more cost-effective. When opportunity costs were included, however, the residential approach was more cost-effective than the SPL approach across all three performance indicators. 
A dissemination meeting held with stakeholders agreed that the SPL and residential approaches are not mutually exclusive - both approaches have their strengths and weaknesses. Safe motherhood training should be based on the strengths of both approaches.

\section{Appendices}

\section{Appendix 1: Types of Cost Measured}

Financial costs - Financial costs are direct expenditures required for the implementation of an activity. In the case of a training activity, financial costs include travel and transportation, per diem, resource person allowances paid to persons involved, and other direct costs such as venue rental, fuel, materials, communications and photocopies.

Opportunity costs - Opportunity costs represent the value of time persons spend in an activity. When salaried staff, such as Ministry of Health personnel, are involved, no direct (or additional) expenditure is needed to cover their time, since their salaries and fringe benefits are already being paid by the $\mathrm{MOH}$ and/or other government entities. These already paid salary and fringe benefit payments are referred to as sunk costs, and not included in the financial costs. Opportunity cost may be expressed either in total hours or hours per individual, or hours multiplied by the associated salary and fringe benefit rates for the individuals involved. Opportunity cost may also be expressed in terms such as the number of other activities (e.g., client visits) that might have been accomplished in a comparable time frame.

Development costs vs. implementation costs - A comprehensive costing analysis should include the costs of developing each training approach and amortize (spread) those costs over the anticipated lifetime of the training programme. In the case of the SPL approach, much of the development work was done with PRIME II technical assistance, and a decision was taken to exclude the development costs for both approaches and measure only the implementation costs that would be required for scaling up. This decision is consistent with other costing analyses of PRIME II interventions, in which technical assistance costs are generally excluded.

Time tracking

For the SPL approach - A 'learner' time tracking tool was designed to record the time required for the following activities:

- Individual reading and review of the modules

- Visits made to learner partners (including time spent waiting for vehicles and travel time from their various health facilities and back to their facilities)

- Trips to their RRTs for discussion on the modules

- Trips for demonstration and clinical practice with their Clinical Instructors.

The SPL learners tracked their time for each activity. During meetings with the learners at the beginning of the study, it was realized that quite a lot of time was spent waiting for RRTs and Clinical Instructors to get ready for their learners during trips for consultation, demonstrations and clinical practice, and so the tool was modified to capture this time. A guide to filling in the time tracking sheets was attached to the sheets themselves to serve as a reminder for learners that they should record waiting time and how to do this. 
For the traditional residential approach - Due to the uniformity of learner time associated with this approach, a learner time tracking tool was not used for this group. Time calculations were based on the revised budget estimates and adjusted based on the mix of service providers participating in the approach.

For the resource persons - Data on time used by RRTs, Clinical Instructors, and managers at the Regional and District Health Management Teams for both approaches was collected retrospectively using a questionnaire, or interview guide and so was based on recall. During visits with these personnel prior to the data collection interview, the PRIME II/HRU team asked RRT members and Clinical Instructors to track the time they spent with learners to help them be able to answer questions about their use of time later. Some RRTs and Clinical Instructors had noted their preparation time and time spent with SPL learners in notebooks and these were used as reference points in responding to questions on their time. 


\section{Appendix 2: Volume of services provided during January 1-December 31 2001, by type of facility}

\begin{tabular}{|c|c|c|c|c|c|c|}
\hline \multirow[b]{2}{*}{ Service } & \multicolumn{3}{|c|}{ Intervention } & \multicolumn{3}{|c|}{ Comparison } \\
\hline & $\begin{array}{c}\text { District } \\
\text { Hospital } \\
(n=2)\end{array}$ & $\begin{array}{l}\text { Health } \\
\text { Centres } \\
(n=19)\end{array}$ & $\begin{array}{l}\text { Total } \\
(n=21)\end{array}$ & $\begin{array}{c}\text { District } \\
\text { Hospital } \\
(n=2)\end{array}$ & $\begin{array}{c}\text { Health } \\
\text { Centres } \\
(n=15)\end{array}$ & $\begin{array}{l}\text { Total } \\
(n=17)\end{array}$ \\
\hline \multicolumn{7}{|c|}{ ANC } \\
\hline Antenatal registrants & 3065 & 5407 & 8472 & 4642 & 3733 & 8375 \\
\hline Total ANC visits & 7150 & 16361 & 23511 & 12198 & 9317 & 21515 \\
\hline $\begin{array}{l}\text { Number of pregnant women } \\
\text { receiving tetanol }\end{array}$ & 4029 & 5693 & 9722 & 6261 & 3553 & 9814 \\
\hline \multicolumn{7}{|c|}{ Labour and Delivery } \\
\hline Normal vaginal delivery & 1009 & 887 & 1896 & 811 & 999 & 1810 \\
\hline Complicated vaginal delivery & 13 & 21 & 34 & 38 & 37 & 75 \\
\hline Caesarean section & 153 & 4 & 157 & 109 & 0 & 113 \\
\hline $\begin{array}{l}\text { Babies first } 6 \text { week } \\
\text { vaccination }\end{array}$ & 1506 & 5517 & 7023 & 988 & 3118 & 4106 \\
\hline \multicolumn{7}{|c|}{ PAC } \\
\hline Induced abortions performed & 0 & 0 & 0 & 89 & 0 & 89 \\
\hline Post natal registrants & 1357 & 2138 & 3495 & 984 & 1741 & 2725 \\
\hline Postabortion care clients & 6 & 7 & 13 & 119 & 10 & 129 \\
\hline $\begin{array}{l}\text { Postabortion care clients } \\
\text { accepting family planning } \\
\text { immediately }\end{array}$ & 0 & 4 & 4 & 24 & 5 & 29 \\
\hline \multicolumn{7}{|c|}{ Family Planning } \\
\hline $\begin{array}{l}\text { New and continuing users of } \\
\text { FP }\end{array}$ & 2661 & 7829 & 10490 & 3487 & 3637 & 7124 \\
\hline Pills & 55 & 1449 & 1504 & 274 & 454 & 728 \\
\hline Condoms (male and female) & 149 & 2300 & 2449 & 235 & 350 & 585 \\
\hline IUD & 207 & 23 & 230 & 18 & 51 & 69 \\
\hline Foaming tablets & 18 & 463 & 481 & 35 & 20 & 55 \\
\hline Injectables & 654 & 6117 & 6771 & 2812 & 3412 & 6224 \\
\hline Norplant & 456 & 76 & 532 & 260 & 76 & 336 \\
\hline Vasectomy & 0 & 0 & 0 & 0 & 0 & 0 \\
\hline Tubal Ligation & 0 & 0 & 0 & 0 & 0 & 0 \\
\hline \multicolumn{7}{|c|}{ Pregnancy complications } \\
\hline Eclampsia & 27 & 0 & 27 & 4 & 3 & 7 \\
\hline Severe malaria & 217 & 7 & 224 & 158 & 46 & 204 \\
\hline Antepartum haemorrhage & 14 & 7 & 21 & 9 & 9 & 18 \\
\hline $\begin{array}{l}\text { Dysfunctional labour } \\
\text { (prolonged/obstructed) }\end{array}$ & 52 & 17 & 69 & 53 & 20 & 73 \\
\hline Uterine rupture & 3 & 37 & 40 & 3 & 30 & 33 \\
\hline Postpartum haemorrhage & 7 & 7 & 14 & 15 & 11 & 26 \\
\hline Postpartum infection (sepsis) & 0 & 18 & 18 & 11 & 1 & 12 \\
\hline Premature births & 9 & 16 & 25 & 5 & 13 & 18 \\
\hline Still Birth & 62 & 7 & 69 & 11 & 7 & 18 \\
\hline Neonatal deaths & 5 & 3 & 8 & 2 & 1 & 3 \\
\hline Ectopic pregnancy & 8 & 0 & 8 & 4 & 0 & 4 \\
\hline Retained placenta & 12 & 8 & 20 & 7 & 10 & 17 \\
\hline $\begin{array}{l}\text { Incomplete abortion (Retained } \\
\text { products) }\end{array}$ & 40 & 7 & 47 & 58 & 10 & 68 \\
\hline Maternal deaths & 7 & 2 & 9 & 4 & 0 & 4 \\
\hline
\end{tabular}

